UNIVERSIDADE TECNOLÓGICA FEDERAL DO PARANÁ PROGRAMA DE PÓS-GRADUAÇÃO EM ENGENHARIA ELÉTRICA E INFORMÁTICA INDUSTRIAL

RENAN HACKBARTH

UMA PROPOSTA DE ROTEAMENTO UTILIZANDO

COMUNICAÇÃO ADAPTATIVA EM REDES SEM FIO MÚLTIPLOS

SALTOS COM MÚLTIPLAS ANTENAS

DISSERTAÇÃO 


\title{
UMA PROPOSTA DE ROTEAMENTO UTILIZANDO COMUNICAÇÃO ADAPTATIVA EM REDES SEM FIO MÚLTIPLOS SALTOS COM MÚLTIPLAS ANTENAS
}

\begin{abstract}
Dissertação apresentada ao Programa de Pósgraduação em Engenharia Elétrica e Informática Industrial da Universidade Tecnológica Federal do Paraná como requisito parcial para obtenção do grau de "Mestre em Ciências" - Área de Concentração: Telemática.
\end{abstract}

Orientadora: Anelise Munaretto Fonseca

\section{CURITIBA}




\section{H188 Hackbarth, Renan}

Uma proposta de roteamento utilizando comunicação adaptativa em redes sem fio múltiplos saltos com múltiplas antenas / Renan Hackbarth. - 2012. 63 f. : il. ; $30 \mathrm{~cm}$

Orientadora: Anelise Munaretto Fonseca.

Dissertação (Mestrado) - Universidade Tecnológica Federal do Paraná. Programa de Pósgraduação em Engenharia Elétrica e Informática Industrial. Curitiba, 2012.

Bibliografia: f. 58-61.

1. Roteadores (Rede de computadores). 2. Redes de computação - Protocolos. 3. Sistemas de comunicação sem fio. 4. Sistemas MIMO. 5. Simulação (Computadores). 6. Engenharia elétrica Dissertações. I. Fonseca, Anelise Munaretto, orient. II. Universidade Tecnológica Federal do Paraná. Programa de Pós-graduação em Engenharia Elétrica e Informática Industrial. III. Título.

CDD (22. ed.) 621.3 
Programa de Pós-Graduação em Engenharia Elétrica e Informática Industrial

Título da Dissertação No: $\mathbf{5 8 8}$

\section{"Uma Proposta de Roteamento Utilizando Comunicação Adaptativa em Redes Sem Fio Múltiplos Saltos"}

por

\section{Renan Hackbarth}

Esta dissertação foi apresentada como requisito parcial à obtenção do grau de MESTRE EM CIÊNCIAS - Área de Concentração: Telemática, pelo Programa de Pós-Graduação em Engenharia Elétrica e Informática Industrial CPGEI - da Universidade Tecnológica Federal do Paraná - UTFPR - Câmpus Curitiba, às $09 \mathrm{~h} 30$ do dia 24 de fevereiro de 2012. O trabalho foi aprovado pela Banca Examinadora, composta pelos professores:
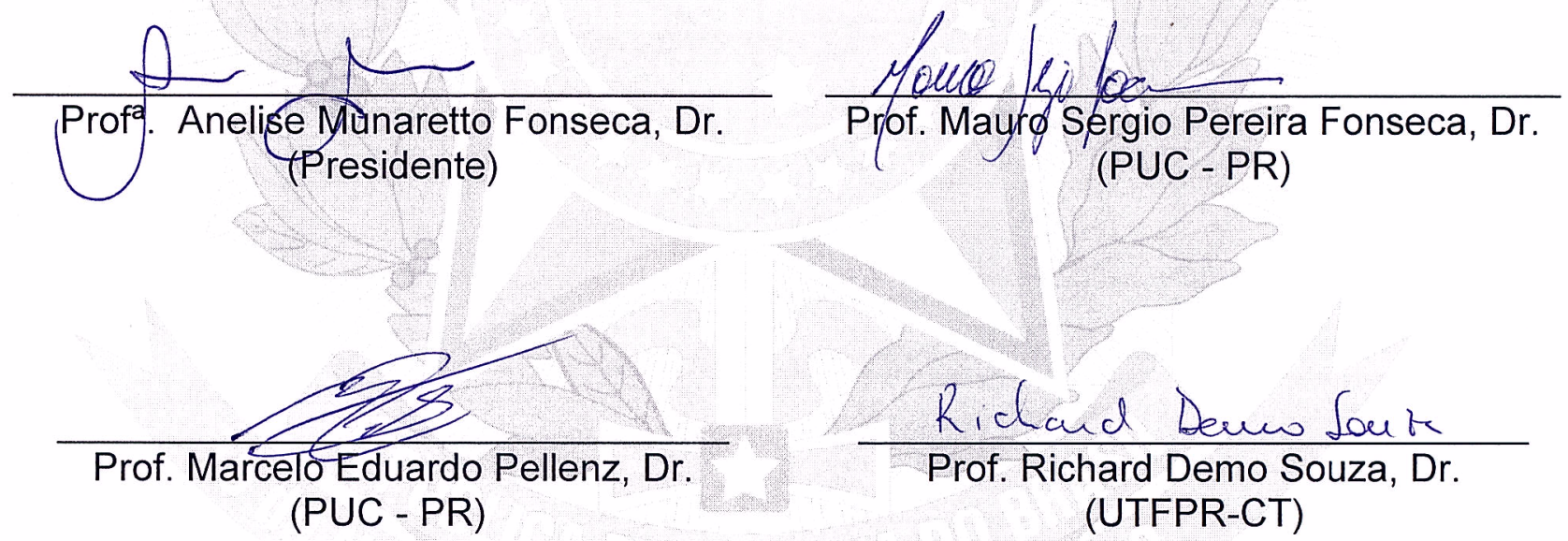

Visto da coordenação:

(UTFPR-CT)

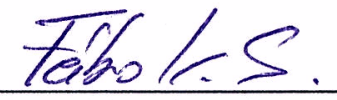

Prof. Fábio Kurt Schneider, Dr.

(Coordenador do CPGEI) 


\section{AGRADECIMENTOS}

À minha orientadora Dra. Anelise Munaretto Fonseca, agradeço primeiramente pela oportunidade que me foi concedida, como também pelo seu apoio, compreensão e suporte oferecido durante todas as etapas deste trabalho.

Ao meu colega Marcos Tomio Kakitani, que sempre se mostrou disposto a ajudar em todos os momentos que precisei. E cuja paciência e colaboração foram essenciais para o desenvolvimento deste trabalho.

À minha família, pelo incentivo e apoio sempre constantes. E a todos aqueles que direta ou indiretamente colaboraram comigo nesta jornada, ou simplesmente acreditaram. 
Cada segundo é tempo para mudar tudo para sempre. (CHAPLIN, Charles). 


\section{RESUMO}

HACKBARTH, Renan. Uma Proposta de Roteamento Utilizando Comunicação Adaptativa em Redes sem Fio Múltiplos Saltos com Múltiplas Antenas. 63 f. Dissertação - Programa de Pósgraduação em Engenharia Elétrica e Informática Industrial, Universidade Tecnológica Federal do Paraná. Curitiba, 2012.

Este trabalho apresenta como proposta uma rede sem fio adaptativa, que utiliza o conceito de métricas inter-camadas na escolha das rotas. Para tal, foram realizadas simulações utilizando o programa computacional Network Simulator - NS. Escolheu-se utilizar o protocolo de roteamento OLSR, do inglês Optimized Link State Routing para realizar o cálculo e escolha das rotas, e o padrão IEEE 802.11g foi escolhido para transmissão de dados. As interações entre as camadas foram alteradas, de modo que o valor da relação interferência sinal ruído, do inglês, Signal-to-Interference Noise Ratio - SINR, seja percebida na camada física e repassada para camada de rede. Quando um elemento móvel recebe um pacote de controle de um determinado vizinho, o valor de SINR calculado representa o estado do enlace entre os dois elementos móveis. Assume-se que cada nó possui conhecimento prévio da taxa de transmissão que irá proporcionar a maior vazão possível, de acordo com o estado do enlace. E com base no conhecimento do estado dos enlaces no percurso fim-a-fim, a camada de rede irá buscar e estabelecer o caminho que proporcione a maior vazão possível. E buscando enfatizar os ganhos gerados pelo modelo proposto, os resultados obtidos nas simulações foram comparados com um modelo de rede não adaptativo, utilizando a versão tradicional do protocolo OLSR descrita pela RFC3626. Também verificou-se o desempenho do modelo proposto, em conjunto com algumas técnicas conhecidas e já estabelecidas de combate aos efeitos do desvanecimento.

Palavras-chave: Inter-camadas, Redes mesh, Protocolo de roteamento OLSR, Simulador NS, Comunicação adaptativa, MIMO. 


\begin{abstract}
HACKBARTH, Renan. A Routing Proposal using Adaptive Communication in Wireless Multihop Networks with Multiple Antennas. 63 f. Dissertação - Programa de Pós-graduação em Engenharia Elétrica e Informática Industrial, Universidade Tecnológica Federal do Paraná. Curitiba, 2012.

This work presents a proposal of a wireless adaptive network which chooses its routes based on a cross-layer metric concept. This proposal was conducted by means of computer simulations and more specifically, using the Network Simulator - NS software. Procedures concerning the addiction and establishment of new routes were handled by the well known routing protocol, Optimized Link State Routing protocol - OLSR. The IEEE 802.11g standard was selected to perform all data transmissions. Interactions between the network layers were modified, so the information regarding the signal-to-interference noise ratio (SINR) detected at the physical layer, is delivered directly at the network layer. When a wireless node receives a routing packet from its neighbor, it calculates the SINR value which represents the link state between these two nodes. It is assumed that each wireless node previously knows the transmission rate, which will ensure the highest throughput regarding the state of link. Once a node gathers sufficient information about the link state of each hop across an end-to-end path, the network layer shall be able to calculate the route which offers the highest throughput. And to evaluate the advantages and disadvantages of this proposal, simulation results were compared to a non-adaptive network model, using the traditional version of the OLSR protocol described in the RFC3626. Also the performance of this proposal was evaluated, combined with already known and established fading reduction techniques.
\end{abstract}

Keywords: Cross-layer, Mesh networks, OLSR routing protocol, NS simulator, Adaptive Communication, MIMO. 


\section{LISTA DE FIGURAS}

FIGURA 1 - DIAGRAMA DE BLOCO REPRESENTATIVO DA TÉCNICA DE DIVER-

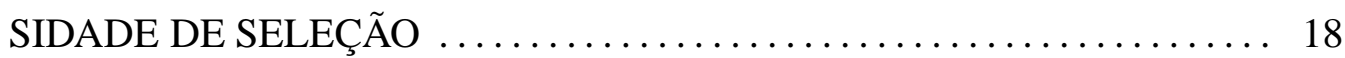

FIGURA 2 - DIAGRAMA DE BLOCO REPRESENTATIVO DA TÉCNICA DE DIVERSIDADE POR REALIMENTAÇÃO OU VARREDURA $\ldots \ldots \ldots \ldots \ldots \ldots$

FIGURA 3 - DIAGRAMA DE BLOCO REPRESENTATIVO DA TÉCNICA DE DIVERSIDADE POR COMBINAÇÃO DE RAZÃO MÁXIMA . . . . . . . . . . 19

FIGURA 4 - DIAGRAMA DE BLOCO REPRESENTATIVO DO ESQUEMA PROPOSTO

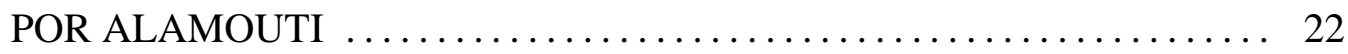

FIGURA 5 - CURVAS DE BER VS. SNR CONSIDERANDO ESQUEMAS DE DIVER-

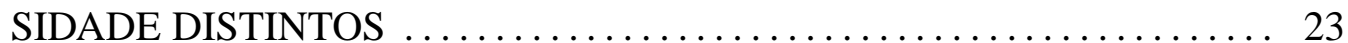

FIGURA 6 - MODELO DO ESQUEMA MIMO - BEAMFORMING . . . . . . . . 24

FIGURA 7 - PROCESSOS DE BROADCAST DAS MENSAGENS DE CONTROLE DO PROTOCOLO ..................................... 30

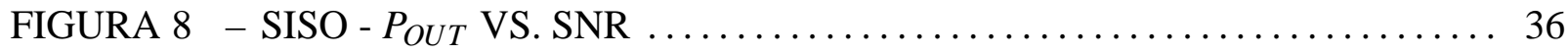

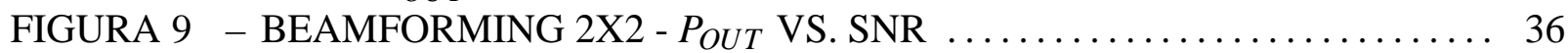

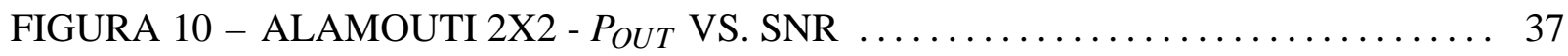

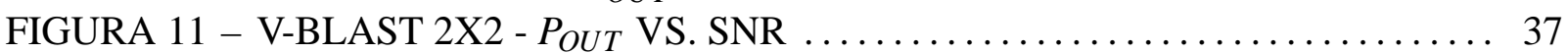

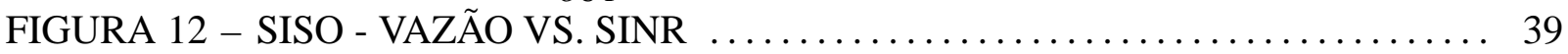

FIGURA 13 - BEAMFORMING 2 X2 - VAZÃO VS. SNR .................. 41

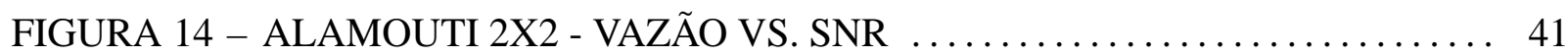

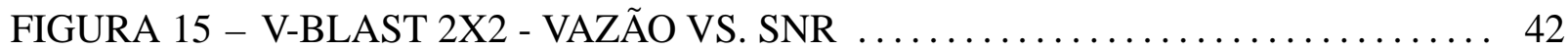

FIGURA 16 - OLSR - PROPAGAÇÃO DA MENSAGEM DE HELLO . . . . . . . . . 42

FIGURA 17 - OLSR - PROPAGAÇÃO DA MENSAGEM DE TC $\ldots \ldots \ldots \ldots \ldots \ldots \ldots .43$

FIGURA 18 - SIMULAÇÕES - CENÁRIO COMPOSTO POR 11 NÓS SEM FIO ...... 46

FIGURA 19 - SIMULAÇÕES - ROTAS ESCOLHIDAS EM CENÁRIO COMPOSTO POR

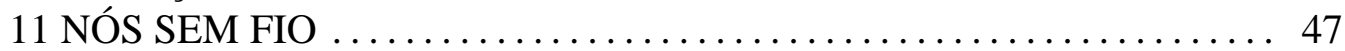

FIGURA 20 - SIMULAÇÕES - CONJUNTO DE DEZ TOPOLOGIAS DISTINTAS DE-

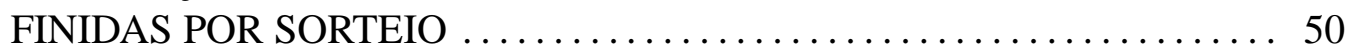

FIGURA 21 - VALORES DE VAZÃO MÉDIA OBTIDOS UTILIZANDO O OLSR PROPOSTO E O OLSR DESCRITO PELA RFC3626 ............... 52

FIGURA 22 - PARÂMETROS DE REDE MEDIDOS UTILIZANDO O OLSR PROPOSTO E O OLSR DESCRITO PELA RFC3626 .................... 53

FIGURA 23 - MIMO - VAZÃO VS. TOPOLOGIA $\ldots \ldots \ldots \ldots \ldots \ldots \ldots \ldots \ldots \ldots \ldots$

FIGURA 24 - MIMO - ATRASO, JITTER, PACOTES PERDIDOS E PACOTES DE CON-

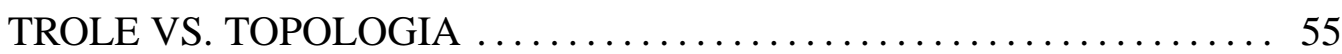




\section{LISTA DE TABELAS}

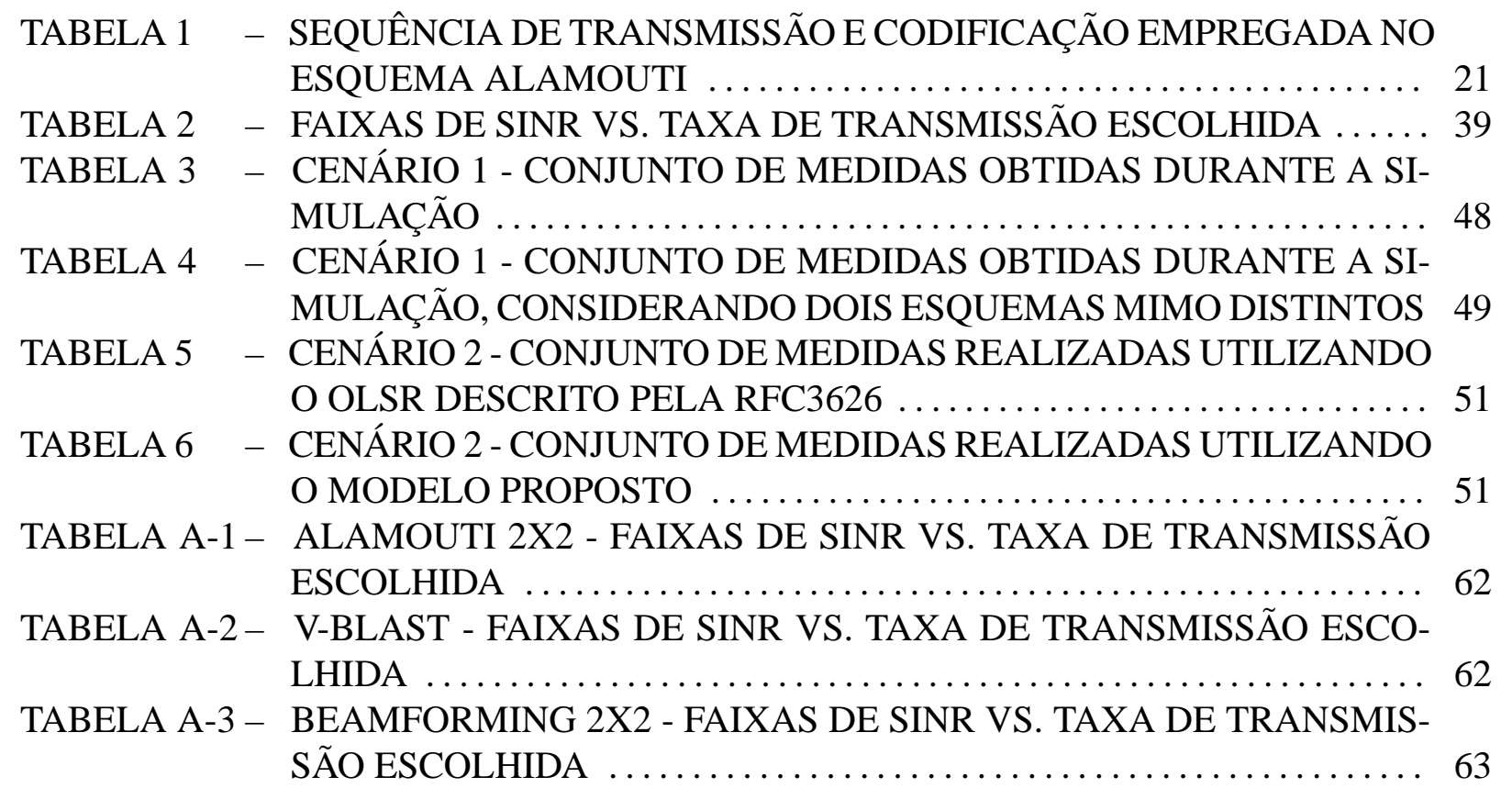




\section{LISTA DE SIGLAS}

STC Space Time Codes

OSI Open Systems Interconnection

ISO International Standards Organization

IEEE Institute of Electrical and Electronic Engineers

BLAST Bell Laboratories Layered Space-Time

MRC Maximal Ratio Combining

MIMO Multiple Input Multiple Output

STTC Space Time Trellis Codes

STBC Space Time Block Codes

BER Bit Error Rate

V-BLAST Vertical-Bell Laboratories Layered Space-Time

DSR Dynamic Source Routing Protocol

AODV Ad Hoc On-Demand Distance Vector

TORA Temporally Ordered Routing algorithm

LAR Location-Aided Routing Protocol

DSDV Destination Sequenced Distance-vector Routing Protocol

STAR Source-Tree Adaptive Routing Protocol

CGSR Cluster-Head Gateway Switch Routing Protocol

OLSR Optimized Link State Routing Protocol

TTL Time to Live

MPR Multipoint Relay

RBAR Receiver-Based AutoRate

RTS Request to Send

CTS Clear to Send 
NS Network Simulator

SINR Signal-to-Interference Noise Ratio

PER Packet Error Rate

SNR Signal-to-Noise Ratio

SISO Simple Input Simple Output

OLSR Optimized Link State Routing Protocol 


\title{
LISTA DE SÍMBOLOS
}

\author{
$\mathrm{Nr} \quad$ número de receptores lineares \\ $\tilde{s}_{1} \quad$ sinal transmitido pela antena 1 \\ $\tilde{s}_{2} \quad$ sinal transmitido pela antena 2 \\ $r_{1} \quad$ sinal recebido pela antena 1 no tempo $t$ \\ $r_{2} \quad$ sinal recebido pela antena 2 no tempo $t+T$ \\ $t \quad$ intervalo de tempo em segundos \\ T Período completo de duração de um símbolo \\ $w_{1} \quad$ variável aleatória complexa representativa do ruído na antena 1 \\ $w_{2} \quad$ variável aleatória complexa representativa do ruído na antena 2 \\ $\gamma_{\min } \quad$ relação sinal ruído mínima para um desempenho aceitável \\ C capacidade \\ $B \quad$ largura de banda \\ $P_{\text {out }} \quad$ probabilidade de outage \\ p função de probabilidade \\ $\gamma \quad$ valor de SNR instantâneo \\ $\bar{\gamma}_{s} \quad$ relação sinal ruído média \\ M ordem de diversidade \\ V Vazão \\ $\mathscr{C} \quad$ custo
}




\section{SUMÁRIO}

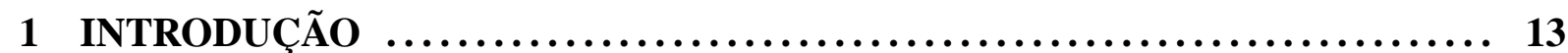

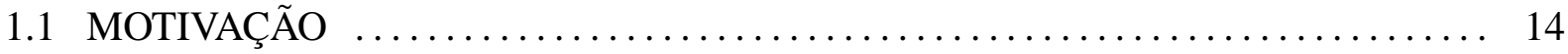

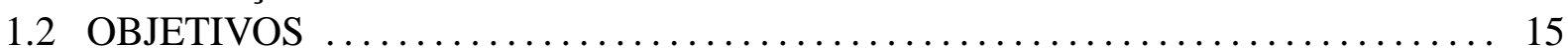

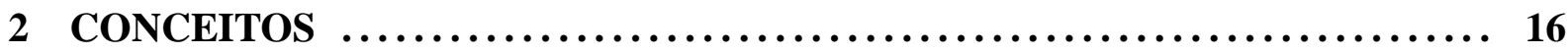

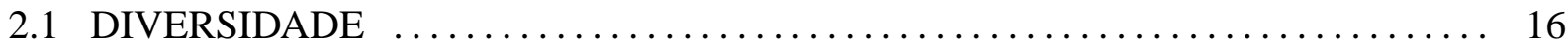

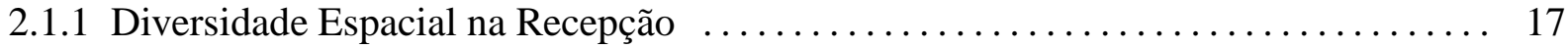

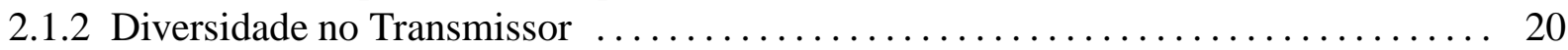

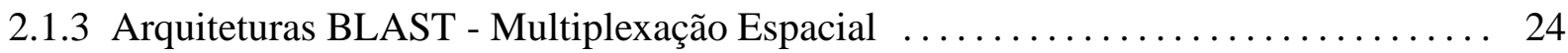

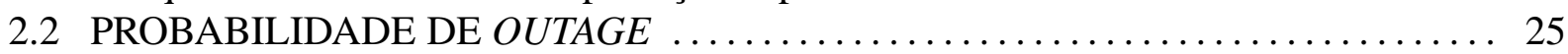

2.3 PROTOCOLOS DE ROTEAMENTO PARA REDES AD HOC $\ldots \ldots \ldots \ldots \ldots \ldots . \ldots 27$

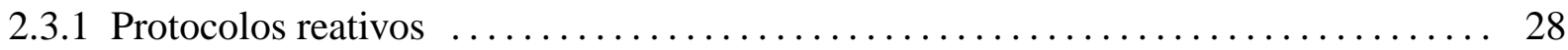

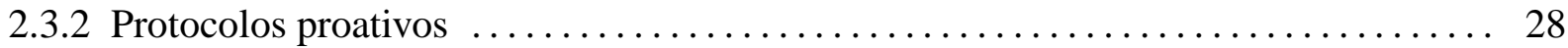

2.3.2.1 Protocolo OLSR - Optimized Link State Routing Protocol $\ldots \ldots \ldots \ldots \ldots \ldots \ldots . \ldots 28$

3 PROPOSTA $\ldots \ldots \ldots \ldots \ldots \ldots \ldots \ldots \ldots \ldots \ldots \ldots \ldots \ldots \ldots \ldots \ldots \ldots \ldots \ldots \ldots \ldots \ldots . . . \ldots \ldots$

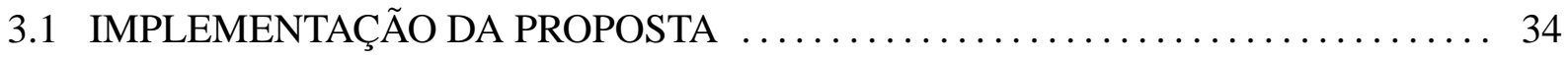

3.1.1 Métrica OLSR e o Modelo de Transmissão Adaptativo $\ldots \ldots \ldots \ldots \ldots \ldots \ldots \ldots \ldots . \ldots \ldots$

3.1.2 Protocolo OLSR - Propagação da nova métrica $\ldots \ldots \ldots \ldots \ldots \ldots \ldots \ldots \ldots \ldots \ldots . \ldots \ldots \ldots \ldots \ldots \ldots \ldots \ldots$

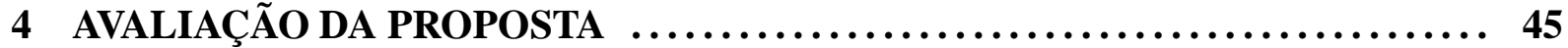

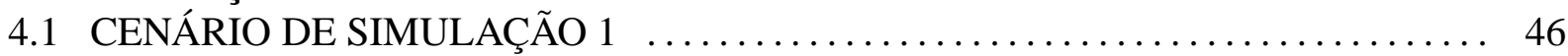

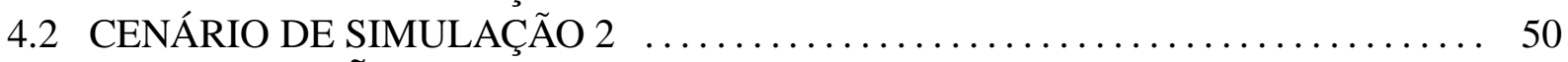

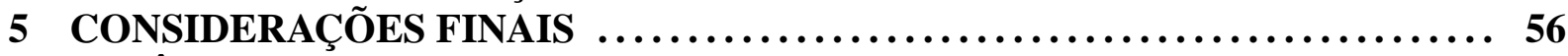

REFERÊNCIAS $\ldots \ldots \ldots \ldots \ldots \ldots \ldots \ldots \ldots \ldots \ldots \ldots \ldots \ldots \ldots \ldots \ldots \ldots \ldots \ldots \ldots . \ldots \ldots$

APÊNDICE A - TABELAS: TAXA DE TRANSMISSÃO X SINR - MIMO ....... 62 


\section{INTRODUÇÃo}

O uso das redes de comunicações de dados em aplicações corporativas se tornou uma realidade quase que inevitável no mundo contemporâneo. Entretanto, para algumas novas modalidades de aplicações e situações específicas, a implantação de um sistema de cabeamento estruturado pode se tornar demasiadamente onerosa, dado a limitação física intrínseca em sua tecnologia, a ponto de ser financeiramente inviável. Em função disso, a demanda no uso de tecnologias sem fio tem crescido de maneira notável nos últimos tempos. Dentre suas principais vantagens, é facilmente visível a capacidade de mobilidade oferecida, cada vez mais necessária entre executivos, empresas e em novas aplicações. Outro ponto importante a salientar, têm-se a praticidade de implantação e alcance a locais, cuja a instalação de uma infraestrutura em cabeamento estruturado não seja possível, ou seja excessivamente complexa de ser implementada.

Novas técnicas e tecnologias vêm constantemente sendo desenvolvidas nessa área de comunicações sem fio, oferecendo diversos recursos capazes de otimizar e facilitar a comunicação de dados, impulsionado esse mercado, e aumentado o número de aderentes a essa solução.

Dentre essas técnicas, podemos citar o uso do conceito de diversidade. Ao realizar uma transmissão, múltiplas cópias do sinal transmitido são propagadas por caminhos distintos até atingirem seu destino. Quando sobre efeito do fenômeno de desvanecimento, canais de comunicação sem fio podem gerar erros significativos nas informações transmitidas. E por sua vez, cada cópia do sinal transmitido sofre diferentes níveis de atenuação. As técnicas de diversidade fazem uso das múltiplas cópias do sinal transmitido, para aumentar a probabilidade de recepção correta da informação enviada (TSE; VISWANATH, 2005). Uma técnica de diversidade que têm conquistado cada vez mais o seu espaço dentre as soluções sem fio atuais são códigos espaço-temporais, do inglês, Space Time Codes - STC. Estes tem como premissa o uso de múltiplas antenas transmissoras, para obter ganhos em termos de diversidade e codificação (BANSAL; TRIVEDI, 2009).

Atualmente as redes sem fio podem ser categorizadas em dois grupos: as redes com infraestrutura e as redes ad hoc (ROYER; TOH, 1999). Nas redes com infraestrutura toda comunicação entre os elementos móveis é feita através de estações conhecidas como estações-base ou ponto 
de acesso. As estações-base não apresentam mobilidade e podem se comunicar entre si.

As redes ad hoc são caracterizadas por um conjunto de nós com a capacidade de se autoorganizar dinamicamente e formar uma topologia temporária, sem a necessidade de uma infraestrutura prévia. Todos os nós pertencentes a topologia são capazes de se comunicar diretamente entre si. Cada nó age como se fosse um roteador (RUBINSTEIN et al., 2006).

Redes ad hoc oferecem grandes vantagens em termos de flexibilidade, baixo custo e robustez. Podem ser rapidamente estabelecidas em lugares de difícil acesso e suportar o impacto causado por catástrofes naturais. Estas características tornam as redes ad hoc muito interessantes em aplicações como operações de resgate e emergência, redes comunitárias de larga escala, operações militares e redes de pequena escala, como salas de aula e ambientes hospitalares.

\subsection{MOTIVAÇÃO}

O mundo das redes sem fio não é somente vantagens. Sua própria natureza dinâmica é responsável por impor seus limites, isso em termos do seu alcance e taxa de transferência de dados da rede.

A arquitetura de rede proposta no modelo de referência OSI (sendo este desenvolvido pela International Standards Organization - ISO) (TANENBAUM, 2003), foi originalmente concebida para uso em redes cabeadas. Portanto, este modelo não considera na sua proposta o impacto causado pelas constantes variações nas condições do meio físico, intrínsecas em ambiente de rede sem fio.

Visando então melhorar o desempenho das redes sem fio, seria interessante que elas se adaptassem a essas condições do meio no qual ela se encontra. Nesse sentido seria interessante utilizar um conceito de métricas inter-camadas, o qual se baseia em uma arquitetura onde diferentes camadas trocam informações a fim de otimizar o desempenho da rede (ZHANG; ZHANG, 2008). Seguindo esse modelo teríamos uma rede com capacidade de autoconfiguração, de forma dinâmica e adaptativa, cuja a escolha do modo e caminho de transmissão sempre será a melhor possível, de acordo com as variáveis do meio na qual ela se insere.

Entretanto, para que um nó calcule a melhor rota para um determinado destino, não basta ter somente conhecimento das condições dos enlaces com seus vizinhos. Da mesma maneira que as condições do enlace com o vizinho podem mudar repentinamente, alterações no percurso entre origem e destino podem aumentar significativamente o custo de uma rota, ou até tornála inválida. Portanto, seria vantajoso que o protocolo de roteamento possua a capacidade de difundir tal informação para todos os nós da rede. Assim cada nó poderá estabelecer o melhor 
caminho para os destinos da rede e ao mesmo tempo, adaptar-se rapidamente as mudanças que ocorrem no meio, recalculando novas rotas caso for necessário.

\subsection{OBJETIVOS}

Este trabalho tem como principal objetivo apresentar os ganhos proporcionados, ao se utilizar uma solução adaptativa inter-camadas para redes sem fio, com o intuito de aumentar a vazão média dos dados transmitidos. Escolheu-se utilizar o padrão IEEE 802.11g (IEEE 802.11g, 2003), por ser um padrão amplamente aceito e utilizado entre os equipamentos de rede sem fio. O cenário escolhido é constituído por um conjunto de elementos com capacidade de transmissão sem fio e posicionamento fixo (sem mobilidade), formando uma infraestrutura na qual diferentes tipos de redes podem se conectar.

O valor da relação sinal ruído mais interferência (SINR) é obtido na camada física e é adicionado nos repositórios do protocolo OSLR. A camada de rede por meio do protocolo de roteamento, fará uso desses dados para calcular e estabelecer as rotas que proporcionem a maior vazão possível. E seguindo com essa premissa, vê-se a necessidade de definir uma nova métrica que seja condizente com o objetivo de aumentar a vazão do tráfego transmitido.

Com base no estado do enlace do nó com seu vizinho, este também irá determinar a taxa de transmissão (sendo oito taxas possíveis: 6Mbits - 54Mbits, definidas pelo padrão 802.11g) que irá proporcionar a maior vazão possível. Faz-se então objetivo dessa proposta, definir e garantir que todos os nós pertencentes a topologia, tenham conhecimento prévio sobre as faixas da relação sinal ruído mais interferência e respectiva taxa de transmissão, que irá gerar a maior vazão de dados possível para o enlace em questão.

O modelo proposto terá seu desempenho medido e avaliado por meio de simulações para posterior comparação com o modelo tradicional, onde a escolha da rota é feita com base no menor número de saltos. Também é objetivo desse trabalho, verificar o desempenho do modelo proposto em conjunto com esquemas MIMO - Multiple Input Multiple Output. Tal combinação poderá gerar ganhos ainda superiores, quando comparada com o uso de ambas técnicas isoladamente. 


\section{CONCEITOS}

Este capítulo apresenta uma breve descrição sobre alguns dos principais conceitos utilizados para compreensão e elaboração deste trabalho. Com esse intuito, introduz-se o uso das técnicas de diversidade nas comunicações sem fio, abordando também esquemas MIMO mais elaborados que envolvam o uso dos Códigos Espaço-Tempo e a Arquitetura BLAST. Na sequência, descreve-se com mais detalhes o conceito de Probabilidade de Outage. E por final, apresentase uma visão geral sobre protocolos de roteamento para redes ad hoc, descrevendo com mais detalhes o protocolo Optimized Link Status Routing - OLSR.

\subsection{DIVERSIDADE}

A diversidade é uma técnica capaz de oferecer uma melhora significativa no enlace de comunicação sem fio, a um custo relativamente baixo. Tem por princípio explorar a natureza aleatória da propagação de rádio e mais especificamente caminhos de sinal independentes (RAPPAPORT, 2002).

Um sinal transmitido por uma determinada fonte pode sofrer uma atenuação muito mais severa, quando comparado com uma cópia do mesmo sinal enviada por um caminho distinto e independente. Com mais de um caminho para selecionar, a relação sinal ruído (SNR) instantânea e média no receptor podem ser melhoradas. As técnicas de diversidade compensam os efeitos do desvanecimento do canal, podendo ser aplicadas tanto no transmissor quanto no receptor.

Existem dois principais tipos de atenuação: a atenuação em pequena escala e a atenuação em larga escala. Atenuações em pequena escala são caracterizadas por flutuações rápidas e profundas de amplitude, ocorridas quando a estação móvel se move por distâncias de apenas alguns comprimentos de onda. Essas atenuações são causadas por múltiplas reflexões do sinal nas proximidades da estação móvel. Para suavizar os efeitos causados por esse tipo de atenuação, utilizam-se técnicas de diversidade microscópica. As atenuações em larga escala são causadas por efeito de sombreamento devido a variações no perfil do terreno e à natureza dos 
arredores. E para suavizar os efeitos causados por esse tipo de atenuação, utilizam-se técnicas de diversidade macroscópica. Ou seja, diferentemente das técnicas de diversidade microscópica, esse tipo de técnica procura amenizar os efeitos da atenuação, causados por fenômenos que agem sobre distâncias bem superiores a alguns comprimentos de onda (RAPPAPORT, 2002).

Dentre as técnicas de diversidade existentes na atualidade, podemos identificar e ressaltar as seguintes grandes áreas (HAYKIN; MOHER, 2008):

- Diversidade espacial

- Diversidade temporal

- Diversidade de frequência

Todas as três categorias citadas acima tem seu merecido grau de importância, entretanto este trabalho possui maior enfoque na técnica de diversidade espacial quando aplicada no receptor. Em função disso a subseção 2.1.1 trás uma descrição mais detalhada sobre essa técnica.

\subsubsection{DIVERSIDADE ESPACIAL NA RECEPÇÃO}

A diversidade espacial é uma das formas mais populares de diversidade usadas em sistemas sem fio. Sistemas de comunicação sem fio convencionais são compostos por uma única antena na estação-base e uma antena móvel próxima ao solo. O conceito de diversidade espacial implica no uso de múltiplas antenas na estação móvel, ou na estação-base, ou em ambas.

A possibilidade de existir uma série de espalhadores de sinal nas proximidades da estação móvel, implica na necessidade de manter uma separação física entre as antenas da estação-base da ordem de dezenas de comprimentos de onda. Tal procedimento busca a descorrelação entre os envoltórios dos sinais recebidos. Já na estação móvel essa distância tem que ser no mínimo de alguns comprimento de onda (RAPPAPORT, 2002).

Métodos de diversidade espacial no receptor, geralmente são classificados em quatro categorias: Combinação de seleção, Diversidade por realimentação ou varredura, Combinação de razão máxima e Diversidade por ganho igual.

- Combinação de seleção

É o método mais simples de diversidade. Basicamente esse sistema é formado por $\mathrm{Nr}$ receptores lineares e um circuito lógico, como mostra o diagrama de blocos na Figura 1. Portanto, 
dadas as $\mathrm{Nr}$ saídas produzidas na recepção de um determinado sinal, o circuito lógico irá somente escolher o sinal proveniente da saída que apresentar a maior SNR instantânea (HAYKIN; MOHER, 2008).

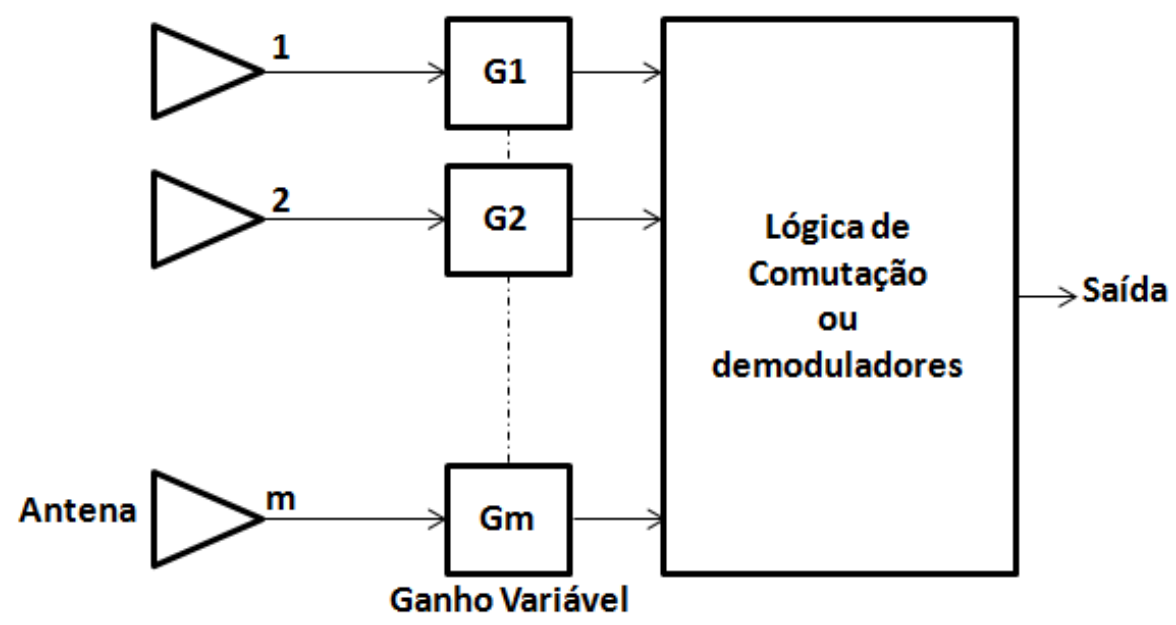

Figura 1: Diagrama de bloco representativo da técnica de combinação de seleção.

Fonte: (HAYKIN; MOHER, 2008)

- Diversidade por realimentação ou varredura

Apresenta um método semelhante ao utilizado pela técnica de diversidade de seleção, no entanto, este "varre"os $\mathrm{Nr}$ sinais em uma sequência fixa, até que seja encontrado um sinal com características acima de um patamar preestabelecido. A Figura 2 representa o diagrama de blocos dessa técnica. O sinal escolhido é recebido até que o mesmo fique abaixo do patamar, o que reinicia o processo de varredura. A grande vantagem desse método é que ele exige somente um único receptor (RAPPAPORT, 2002).

- Combinação de Razão Máxima

Em termos de desempenho a técnica de diversidade de seleção não é considerada ótima. Isso se deve pela sua característica de ignorar a informação proveniente de todos os receptores, exceto aquele que apresentar a maior relação sinal ruído. Tal limitação é atenuada pela técnica de combinação de razão máxima, do inglês Maximal Ratio Combining - MRC (HAYKIN; MOHER, 2008).

Neste sistema os sinais dos $N r$ receptores são pesados de acordo com suas razões individuais entre tensão do sinal e potência do ruído. Na sequência, o resultados dessas razões 


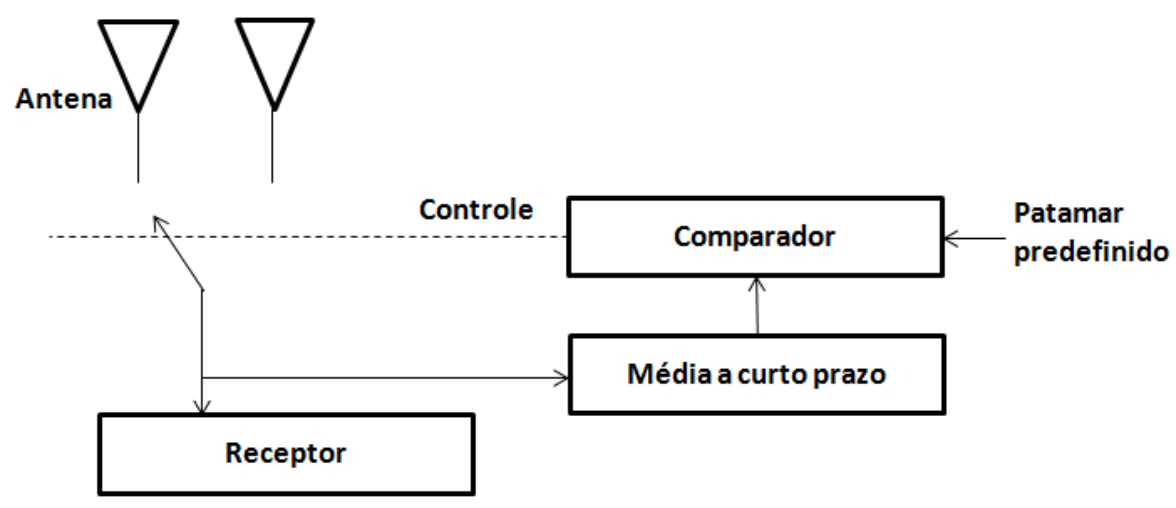

Figura 2: Diagrama de bloco representativo da técnica de diversidade por realimentação ou varredura.

Fonte: (HAYKIN; MOHER, 2008)

individuais deverão ser co-faseados para posteriormente serem somados. Este processo normalmente exige um receptor individual e um circuito de fase para cada elemento da antena. A Figura 3 representa o diagrama de blocos dessa técnica.

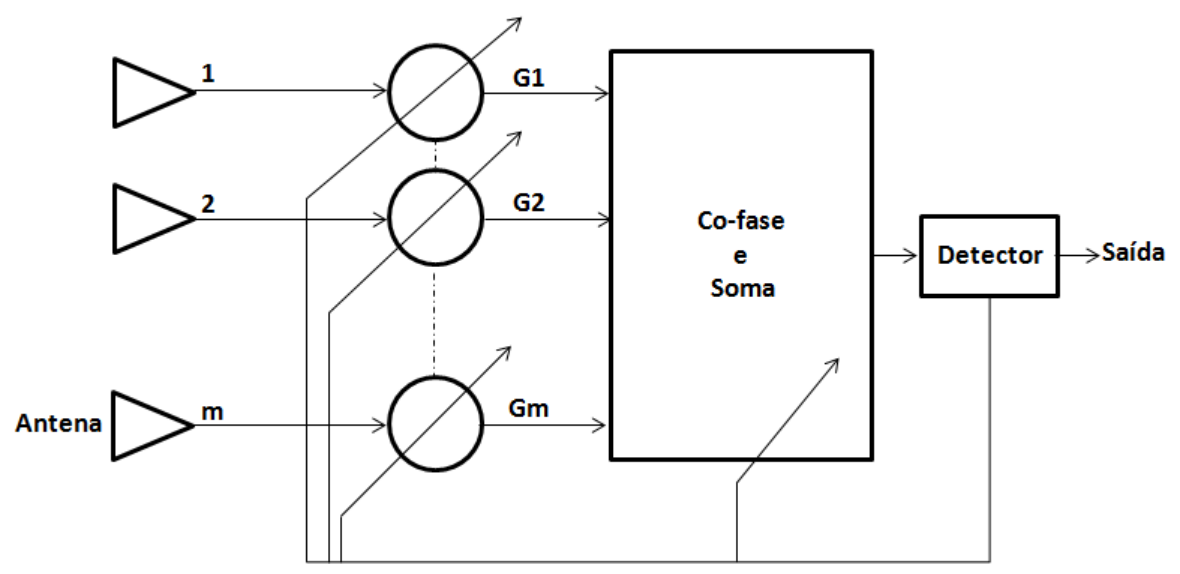

Figura 3: Diagrama de bloco representativo da técnica de diversidade por combinação de razão máxima.

Fonte: (HAYKIN; MOHER, 2008)

A combinação de razão máxima produz uma SNR de saída igual à soma das SNRs individuais. Tal procedimento permite que mesmo quando nenhuma das SNRs individuais apresentar um valor aceitável, ainda assim a combinação das mesmas pode produzir um valor satisfatório (RAPPAPORT, 2002). Consequentemente quanto maior for o número de antenas, maior será a probabilidade de gerar um valor de SNR resultante aceitável.

- Diversidade por ganho igual

Nesse tipo de técnica os sinais dos $N r$ receptores são pesados de acordo com um mesmo 
fator, sendo este independente da amplitude do sinal. Entretanto, para evitar que o sinais se auto-cancelem, estes deverão ser co-faseados para posteriormente serem somados. Portanto, similar a técnica de combinação de razão máxima, esta técnica permite que o receptor explore os sinais recebidos simultaneamente em cada antena receptora e produza um sinal resultante com características únicas. No entanto seu desempenho é inferior a técnica de combinação de razão máxima (RAPPAPORT, 2002).

\subsubsection{DIVERSIDADE NO TRANSMISSOR}

A tecnologia de múltiplas antenas conhecida como MIMO tem por finalidade aumentar a capacidade do enlace sem fio, inserindo diversidade e multiplexação espacial. Essa técnica tem sido considerada uma das mais importantes soluções para aumentar a taxa de transmissão em redes sem fio IEEE 802.11 (AKYILDIZ; WANG, 2008).

$\mathrm{Na}$ maioria das aplicações em sistemas de comunicação sem fio, como por exemplo no acesso à Internet, o fluxo de informações geralmente será muito maior da estação rádio-base (transmissor) para a estação móvel (receptor) do que no sentido contrário. E para contornar os efeitos do desvanecimento do sinal nesse ambiente, o uso de múltiplas antenas no receptor pode se tornar um tanto complexo, ou até ser inviável. Portanto, além das técnicas introduzidas na Seção 2.1, diferentes esquemas foram propostos com esse objetivo. Esses esquemas são aplicados no elemento transmissor, sendo que dentre elas se destacam os códigos espaço-tempo e o esquema MIMO conhecido como Beamforming.

\section{- Códigos Espaço-Tempo}

Através do uso de múltiplas antenas e codificação do canal, os códigos espaço-tempo empregam redundância no domínio do espaço e tempo respectivamente (BANSAL; TRIVEDI, 2009). Dependendo de como a transmissão for realizada, os códigos espaço-tempo podem ser classificados em duas categorias (HAYKIN; MOHER, 2008): códigos espaço-tempo de treliça, do inglês Space Time Trellis Codes - STTC, e os códigos espaço-tempo de bloco, do inglês Space Time Block Codes - STBC.

\section{Código Espaço-Tempo de Treliça}

Os códigos espaço-tempo de treliça (TAROKH; SESHADRI; CALDERBANK, 1998) tem por princípio combinar o processamento do sinal no receptor, com técnicas de codificação apropriadas para o uso de múltiplas antenas no transmissor. Apresentam ganhos 
de diversidade e codificação, principalmente em ambientes caracterizados por baixos valores de desvanecimento. Em contrapartida, exigem alta complexidade no processo de decodificação (HAYKIN; MOHER, 2008).

\section{Códigos Espaço-Tempo de Bloco}

Os códigos espaço-tempo de bloco são caracterizados por realizarem a transmissão do sinal em blocos (HAYKIN; MOHER, 2008). É uma técnica simples capaz de gerar ganhos significativos de diversidade, sem aumentar demasiadamente a complexidade do processo de decodificação. Em contrapartida, não gera ganhos significativos no processo de codificação (BANSAL; TRIVEDI, 2009). Um importante exemplo de código de bloco espaço-tempo em termos de desempenho e simplicidade, é o código Alamouti.

O esquema proposto por Siavash M. Alamouti (ALAMOUTI, 1998) utiliza duas antenas transmissoras e M antenas receptoras. É capaz de prover ganhos de diversidade na ordem de 2M (sendo M, o número de antenas no receptor), sem fornecer qualquer realimentação do receptor para o transmissor e com complexidade computacional reduzida. A Figura 4 apresenta o diagrama de bloco do esquema Alamouti.

A codificação é feita a cada dois símbolos. Com esse objetivo, em um determinado instante dois sinais são simultaneamente transmitidos pelas duas antenas. O sinal transmitido pela antena 1 é denotado por $\tilde{s}_{1}$ e pela antena 2 por $\tilde{s}_{2}$. No próximo período de símbolo o sinal $-\tilde{s}_{2}^{*}$ é transmitido pela antena 1 e o sinal $\tilde{s}_{1}^{*}$ é transmitido pela antena 2 , sendo que o operador $(*)$ representa a operação do conjugado complexo. Esta sequência é apresentada de forma mais clara na Tabela 1 .

Tabela 1: Tabela representativa da sequência de transmissão e codificação empregada no esquema Alamouti.

\begin{tabular}{ccc}
\hline \hline Tempo & Antena 1 & Antena 2 \\
\hline \hline $\mathrm{t}$ & $\tilde{s}_{1}$ & $\tilde{s}_{2}$ \\
$\mathrm{t}+\mathrm{T}$ & $-\tilde{s}_{2}^{*}$ & $\tilde{s}_{1}^{*}$ \\
\hline
\end{tabular}

Fonte: (ALAMOUTI, 1998)

Logo após a transmissão, os sinais recebidos nas antenas receptoras podem ser expressos respectivamente por (1) e (2):

$$
\begin{gathered}
r_{1}=r(t)=h_{1} \tilde{s}_{1}+h_{2} \tilde{s}_{2}+w_{1}, \\
r_{2}=r(t+T)=-h_{1} \tilde{s}_{2}^{*}+h_{2} \tilde{s}_{1}^{*}+w_{2},
\end{gathered}
$$




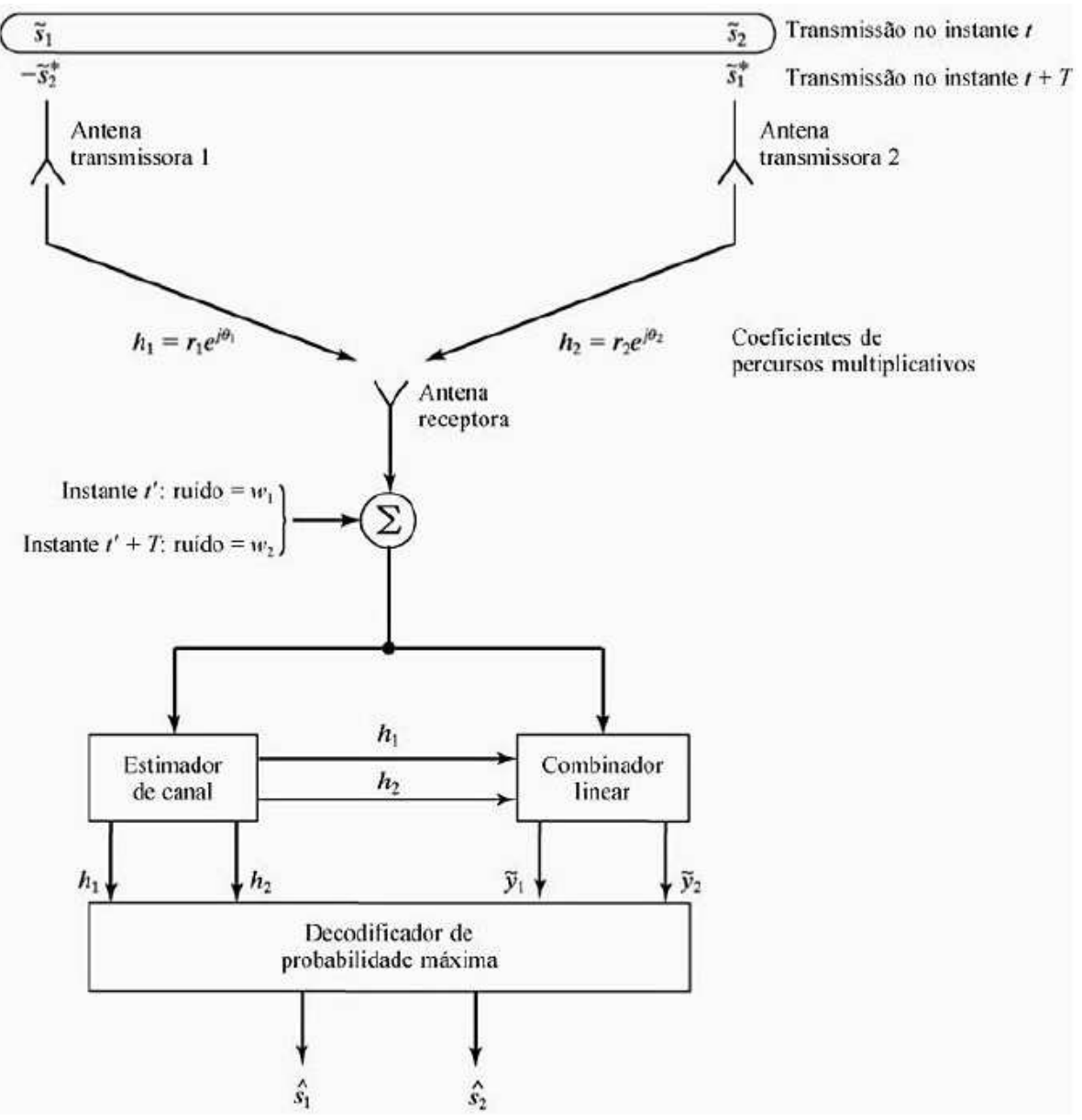

Figura 4: Diagrama de bloco representativo do esquema proposto por Alamouti.

Fonte: (HAYKIN; MOHER, 2008)

onde $r_{1}$ e $r_{2}$ são os sinais recebidos nos tempos $t$ e $t+T$ respectivamente. O canal entre as antenas transmissora 1 e receptora 1 é representado por $h_{1}$, enquanto o canal entre as antenas transmissora 2 e receptora 2 é representado por $h_{2}$. E $w_{1}$ e $w_{2}$ são variáveis aleatórias complexas representando o ruído e interferência no receptor.

Já no processo de decodificação do sinal recebido o esquema Alamouti utiliza a técnica MRC (ALAMOUTI, 1998). Tal processo é representado na Figura 4 pelos blocos: Estimador de Canal e Combinador Linear. A saída destas estruturas alimentam o Detector de Máxima Verossimilhança, o qual estimará os sinais e com probabilidade de erro mínima. Estes sinais são representados pelas equações 3 e 4:

$$
\begin{aligned}
& \tilde{s}_{1}=h_{1}^{*} r_{1}+h_{2} r_{2}^{*}, \\
& \tilde{s}_{2}=h_{2}^{*} r_{1}-h_{1} r_{2}^{*} .
\end{aligned}
$$

O esquema Alamouti é muito vantajoso do ponto de vista de sua praticidade de implanta- 
ção. Considerando um cenário usual de comunicação composto por uma única estaçãobase e várias estações móveis, o esquema Alamouti permite de uma forma muito mais prática adicionar uma segunda antena na estação-base, e gerar um ganho de diversidade para todas estações móveis. Para uma mesma potência de transmissão, o desempenho do esquema Alamouti é próximo do alcançado utilizando a técnica MRC (com uma antena transmissora e duas receptoras). Como ilustrado na Figura 5 pelas curvas de taxa de erro de bit, do inglês Bit Error Rate - BER, o desempenho do esquema Alamouti é $3 \mathrm{~dB}$ inferior quando comparado com o MRC. Tal diferença de desempenho, decorre da a potência total transmitida pelas duas antenas no esquema Alamouti (ALAMOUTI, 1998), ser igual a potência utilizada para transmitir pela única antena no caso com MRC. Essa configuração da potência de trasmissão foi realizada para que a comparação entre essas duas técnicas seja justa.

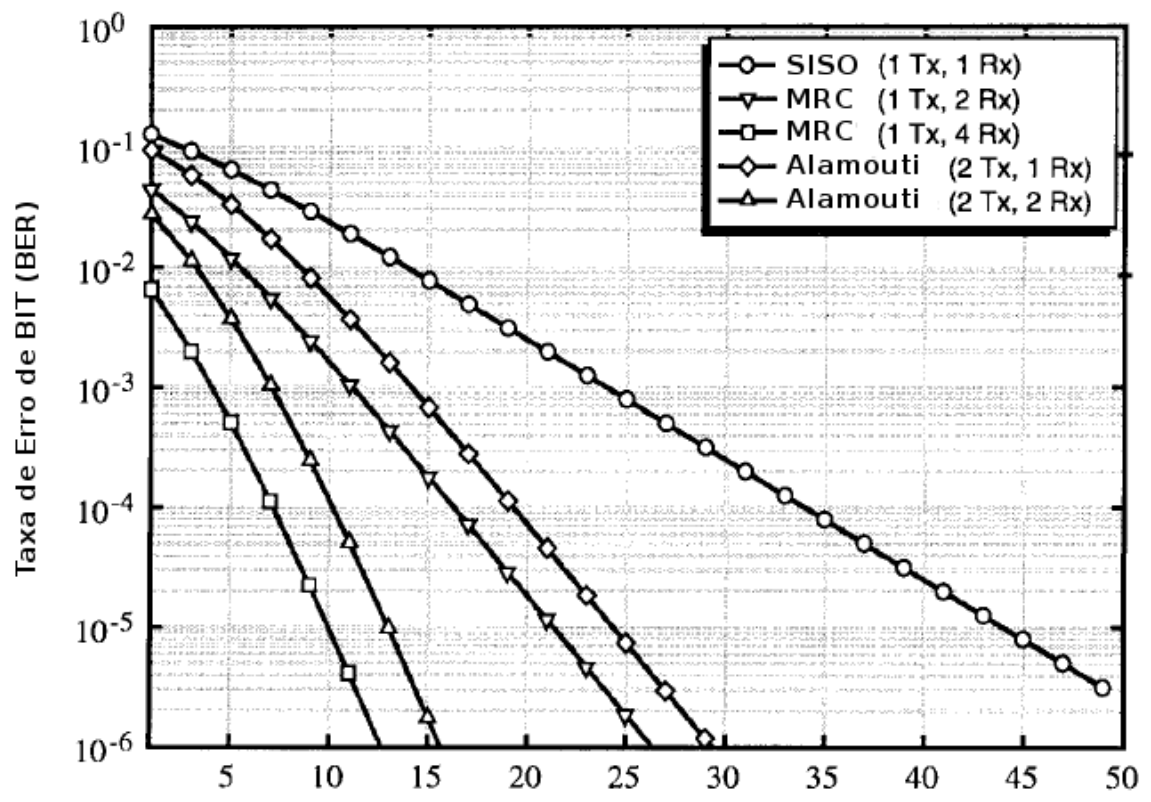

Figura 5: Curvas de BER para uma faixa de valores de SNR, considerando esquemas de diversidade distintos.

Fonte: (ALAMOUTI, 1998)

Para fins de comparação, a Figura 5 também apresenta o desempenho da técnica MRC, com uma antena transmissora e quatro receptoras e o esquema Alamouti com duas antenas transmissoras e duas antenas receptoras. Mais uma vez a técnica MRC apresentou melhor desempenho na relação BER vs. SNR (3dB superior), em função da potência total transmitida pelas duas antenas no esquema Alamouti (ALAMOUTI, 1998), ser igual a potência utilizada para transmitir pela única antena no caso com MRC.

- O Esquema MIMO Beamforming 
O esquema MIMO conhecido como Beamforming tem por princípio utilizar múltiplas antenas no transmissor para obter ganhos de diversidade. Nesse sentido, um peso distinto é atribuído para cada símbolo transmitido por cada antena transmissora. A Figura 6 ilustra esse processo.

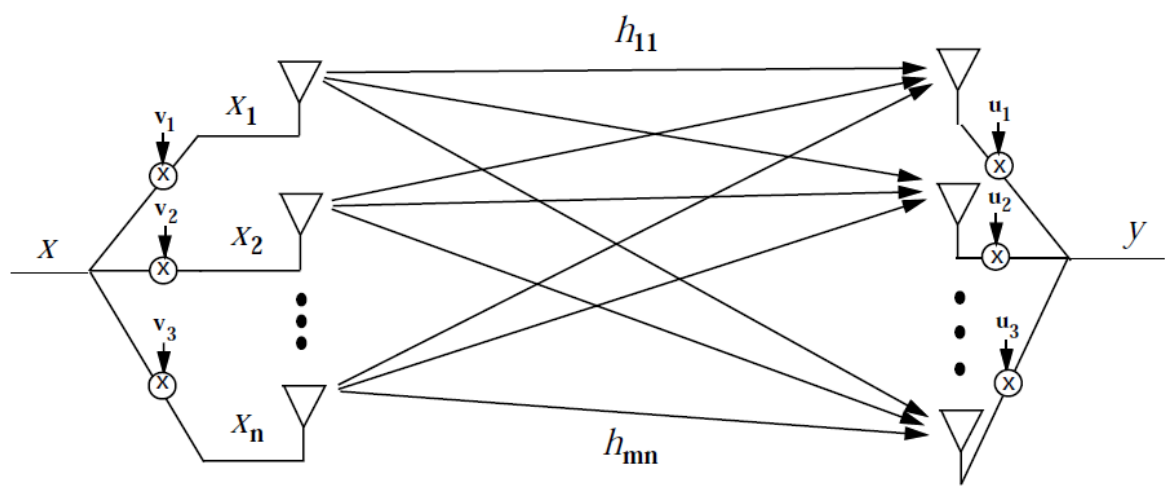

Figura 6: Modelo representativo do esquema MIMO - Beamforming.

Fonte: (GOLDSMITH, 2005)

Como pode ser observado na Figura 6, o símbolo $x$ é enviado pela antena $i$ com peso $v_{i}$. No receptor esse sinal é recebido pela antena $i$, e é "pesado"em função de $u_{i}$. O sinal resultante no receptor é representado pela equação:

$$
y=\mathbf{u}^{*} H \mathbf{v} x+\mathbf{u}^{*} \mathbf{n},
$$

onde $\mathbf{n}$ representa o ruído percebido na antena receptora, $H$ é a matriz do canal e $\mathbf{u}$ e $\mathbf{v}$ são vetores formados por números complexos (os quais representam os pesos atribuídos). O símbolo de cada antena é multiplicado por um número complexo, que corresponde a inversa de fase do canal. Assim, a técnica Beamforming garante ganhos de diversidade pela combinação coerente dos sinais recebidos pelos múltiplos percursos, que resultam na soma construtiva dos mesmos no receptor. Tipicamente, assume-se que o receptor tenha conhecimento do canal.

\subsubsection{ARQUITETURAS BLAST - MULTIPLEXAÇÃO ESPACIAL}

Arquiteturas BLAST, do inglês Bell Laboratories Layered Space-Time, utilizam códigos de correção de erro direto de uma dimensão padrão e um esquema de cancelamento de interferência de baixa complexidade para construir e decodificar poderosos códigos espaço-tempo bidimensionais (HAYKIN; MOHER, 2008). Esses sistemas MIMO oferecem um grande aumento de eficiência espectral, desde que o sistema opere em um ambiente com uma rica difusão Rayleigh. É importante também que sejam utilizadas estruturas de código apropriadas e que nos esquemas de cancelamento de interferência, estejam disponíveis decisões livres de erro.

Dentre as implementações existentes da arquitetura BLAST, vale citar a BLAST Diagonal 
(D-BLAST), BLAST Vertical (V-BLAST) e a Turbo BLAST. Como o esquema V-BLAST será utilizado na atual proposta, o item a seguir faz uma breve descrição sobre o mesmo.

\section{- Arquitetura V-BLAST}

A arquitetura V-BLAST, do inglês Vertical-Bell Laboratories Layered Space-Time, é considerada a primeira implementação prática de comunicações sem fio MIMO, do inglês Multiple Input Multiple Output, para demonstrar eficiência espectral tão alta quanto $40 \mathrm{bit} / \mathrm{s} / \mathrm{Hz}$ em tempo real. Como no V-BLAST não existem operações cíclicas ao logo do tempo, ele reduz significativamente a complexidade do sistema quando comparado com o D-BLAST. E além disso, no transmissor V-BLAST cada antena transmite sua própria subsequência de dados codificada independentemente.

\subsection{PROBABILIDADE DE OUTAGE}

Para melhor compreender o conceito de probabilidade de outage, é interessante ter uma breve noção sobre dois temas: capacidade e capacidade com outage. A capacidade, introduzida por Claude Shannon nos conceitos da Teoria da Informação, é a taxa máxima de transmissão que pode ser alcançada em um canal com probabilidade de erro arbitrariamente pequena. Sendo que qualquer taxa de transmissão superior à capacidade do canal não pode ser atingida sem que a probabilidade de erro seja diferente de zero. Já a capacidade com outage pode ser definida como a taxa máxima que uma mensagem pode ser transmitida em um canal com certa probabilidade de outage. De modo que a probabilidade de outage, corresponde à probabilidade de que a mensagem recebida não seja decodificada com probabilidade de erro suficientemente imperceptível. Tal conceito se aplica a canais de desvanecimento lento, ou seja, quando o valor de SNR instantâneo é constante durante um grande número de transmissões (GOLDSMITH, 2005). Assim, especificamente o transmissor mantém um valor de SNR mínimo $\gamma_{\text {min }}$, para o qual codifica os dados segundo a seguinte equação:

$$
C=B \times \log _{2}\left(1+\gamma_{\min }\right),
$$

onde $C$ é a capacidade de transmissão (em bits por segundo - bps) e $B$ representa a largura de banda. A mensagem enviada é recebida corretamente no receptor, caso a SNR instantânea recebida for maior ou igual a $\gamma_{\text {min }}$ (FOSCHINI et al., 2003) (VARAIYA; P.P., 1968). E caso o valor de SNR no destino for inferior a $\gamma_{\text {min }}$, os bits recebidos não poderão ser decodificados corretamente e o receptor entra em outage. Assim a probabilidade de outage é dada por:

$$
P_{\text {out }}=p\left(\gamma<\gamma_{\text {min }}\right),
$$


sendo que $P_{\text {out }}$ caracteriza a probabilidade de outage, $p$ representa a função de probabilidade e o parâmetro $\gamma$ indica o valor de SNR instantâneo recebido. Já $\gamma_{\min }$ é um parâmetro de design do sistema, representa a relação sinal ruído mínima para um desempenho aceitável e é escolhido de acordo com a necessidade da aplicação.

Ao considerarmos um canal sujeito ao modelo de desvanecimento Rayleigh, a probabilidade de outage em um sistema com única antena transmissora e receptora (SISO) é dada por (GOLDSMITH, 2005):

$$
P_{\text {out }}=1-e^{-\gamma_{\min } / \bar{\gamma}_{s}}
$$

onde $\gamma_{\min }$ representa a relação sinal ruído mínima para um desempenho aceitável e $\bar{\gamma}_{s}$, a relação sinal ruído média. Portanto, a partir equação de capacidade (equação 6) podemos isolar $\gamma_{\min } \mathrm{e}$ ao substituírmos o mesmo na equação (8), foi possível calcular a probabilidade de outage para um faixa de valores de SNR, como mostra:

$$
P_{\text {out }}=1-e^{-\left(2^{C}-1\right) / \bar{\gamma}_{s}}
$$

Neste trabalho a capacidadde $(C)$ representa taxa máxima de transmissão dos elementos que compõem o sistema, a qual depende do modo de transmissão utilizado.

Apesar da probabilidade de outage ser definida para um bloco de mensagem de tamanho infinto, diversos trabalhos como (KNOPP; HUMBLET, 2000), (MALKAMAKI; LEIB, 1999) e (ROSIERS; SIEGEL, 2004) mostraram que a probabilidade de outage é capaz de estimar de forma bastante realista a taxa de erro de quadro (FER), quando códigos corretores de erro de alto desempenho são empregados mesmo com blocos relativamente curtos. Assim, para efeitos desse estudo, considerou-se que os valores de $P_{\text {out }}$ são uma boa aproximação para a FER.

E como o presente trabalho inclui nos seus objetivos cenários que fazem uso de esquemas MIMO (conceito introduzido na seção 2.1), também foram capturados valores de $P_{\text {out }}$ considerando esses sistemas. Portanto, ao considerarmos um sistema que implemente a técnica de diversidade conhecida como Maximal Ratio Combining - MRC, os valores de $P_{\text {out }}$ considerando um modelo de desvanecimento Rayleigh é calculado por (GOLDSMITH, 2005):

$$
P_{\text {out }}=1-e^{-\gamma_{\min } / \bar{\gamma}_{s}} \sum_{k=1}^{M} \frac{\left(\gamma_{\min } / \bar{\gamma}_{s}\right)^{k-1}}{(k-1) !}
$$

onde $M$ representa o número de antenas receptoras. Sendo que é através dessa variável que é possível calcular o valor da probabilidade de outage variando o número de antenas receptoras. Por exemplo, para duas antenas receptoras $M=2$ e para quatro antenas receptoras $M=4$.

E para obter os valores de $P_{\text {out }}$ em um sistema que implemente o esquema MIMO conhe- 
cido como V-BLAST, considerando duas antenas transmissoras e duas antenas receptoras (2x2), utilizou-se (LOYKA; GAGNON; MEMBER, 2004):

$$
P_{\text {out }}=1-\left[\left(1+\gamma_{\min } / \bar{\gamma}_{s}\right) e^{-\gamma_{\min } / \bar{\gamma}_{s}}\right]^{2}
$$

Vale a pena enfatizar que a equação (11) também considera um modelo de desvanecimento Rayleigh.

Até então no presente capítulo, foram discutidos conceitos importantes para melhor compreensão dos procedimentos realizados nesse trabalho. Porém, isso do ponto de vista da camada de acesso à rede. A seguir na seção 2.3 serão discutidos alguns conceitos competentes à camada de rede, mais especificamente, sobre protocolos de roteamento para redes ad hoc.

\subsection{PROTOCOLOS DE ROTEAMENTO PARA REDES AD HOC}

As redes ad hoc são compostas por nós com capacidade de mobilidade arbitrária. Sendo que o estado do enlace de comunicação entre os elementos que compõem essa rede, é estabelecido em função de diversas variáveis, entre elas: a distância entre os nós da rede, nível de potência de transmissão e interferência entre nós vizinhos. Portanto, a capacidade de mobilidade dos nós, juntamente com variabilidade dos estados dos enlaces, resulta em uma rede caracterizada por mudanças rápidas e imprevisíveis em sua topologia. Tal característica, exige o uso de um protocolo de roteamento capaz de difundir as atualizações das rotas muito mais rapidamente e de maneira precisa. Consequentemente, protocolos para redes com fio não são capazes de suprir de forma satisfatória as necessidades impostas pelas redes ad hoc (RUBINSTEIN et al., 2006).

Pesquisas envolvendo roteamento em redes ad hoc, normalmente abrangem as necessidades clássicas de roteamento, ou seja, encontrar os caminhos mais curtos utilizando métodos robustos. Porém ao mesmo tempo, incluem as necessidades particulares de suporte a mobilidade, tais como segurança, duração da bateria e prevalência da conectividade em um único sentido (HUITEMA, 2000).

A classificação dos protocolos de roteamento em redes ad hoc pode ser realizada de diversas maneiras. Porém, um grande número de autores (SHAH et al., 2008) (ROYER; TOH, 1999) (LATIFF; FISAL, 2003) procuram classificá-los de acordo com a estratégia de roteamento. Portanto, os protocolos de roteamento normalmente são incluídos em duas grandes categorias: proativos ou orientados a tabelas, reativos ou orientados a demandas. 


\subsubsection{PROTOCOLOS REATIVOS}

Protocolos reativos, diferentemente dos protocolos proativos, estabelecem rotas para os destinos somente quando existe demanda para tal. Quando um dos nós desejar enviar dados para um determinado destino, este deverá iniciar um processo de descoberta da rota. Assim que a rota estiver estabelecida, esta será mantida até que o destino se torne inacessível, ou a rota expire pelo não uso da mesma (BELDING-ROYER, 2003) (ROYER; TOH, 1999).

São exemplos de protocolos reativos projetados para redes ad hoc: DSR (JOHNSON; MALTZ, 1996), AODV (PERKINS; ROYER, 1999), TORA (PARK; CORSON, 1997) e LAR (KO; VAIDYA, 1998).

\subsubsection{PROTOCOLOS PROATIVOS}

Protocolos proativos procuram manter de forma consistente e atualizada, as informações de roteamento entre os nós pertencentes a rede. Cada nó mantem armazenado em sua memória uma ou mais tabelas de roteamento referente aos demais nós da rede. E para manter a consistência dos dados armazenados nestas tabelas são enviados pacotes de atualização pela rede. Tais atualizações podem ser enviadas periodicamente, como também geradas por algum evento da rede (CHLAMTAC, 2003).

São exemplos de protocolos proativos projetados para redes ad hoc: DSDV (PERKINS; BHAGWAT, 1994), STAR (GARCIA-LUNA-ACEVES; SPOHN, 1999), CGSR (CHIANG et al., 1997) e OLSR (JACQUET; MUHLETHALER; CLAUSEN, 2001).

$\mathrm{Na}$ atual proposta escolheu-se utilizar o protocolo OLSR, em função do seu melhor desempenho em redes maiores e mais densas (RUBINSTEIN et al., 2006). A próxima seção trás uma breve descrição sobre suas características e funcionalidades.

\subsubsection{Protocolo OLSR - Optimized Link State Routing Protocol}

O protocolo de roteamento Optimized Link State Routing Protocol - OLSR (JACQUET; MUHLETHALER; CLAUSEN, 2001), trata-se de uma otimização do algoritmo link-state para redes ad hoc. Como descrito pela RFC 3626 (CLAUSEN; JACQUET, 2003), utiliza como métrica o número de saltos entre a origem e destino. Assim, quando um elemento da rede desejar enviar seus dados para um determinado destino, este escolherá o caminho que apresentar o menor número de saltos possível. Essa métrica foi escolhida como padrão da RFC 3626 principalmente (entre outros fatores) pela sua facilidade de manipulação, independência com 
relação ao tráfego transmitido e por ser pouco variável no tempo quando consideramos uma topologia formada por elementos fixos.

Cada nó da rede mantém uma tabela de roteamento atualizada, calculada com base nas informações encontradas nos repositórios do OLSR. Essa tabela deve conter todos os destinos possíveis e conhecidos da rede. Sua atualização ocorre sempre que houver qualquer alteração em algum dos seguintes repositórios: Conjunto de Vizinhos, Conjunto de Links, Conjunto de Vizinhos a dois Saltos, Repositório de Informações de Topologia e o Repositório de Associação de Múltiplas Interfaces. Por sua vez, os repositórios são atualizados através das mensagens de HELLO e TC pertencentes ao protocolo OLSR e trocadas entre os nós da rede.

A mensagem de HELLO é utilizada pelo protocolo OLSR na detecção e manutenção dos enlaces entre os nós e seus vizinhos. Com esse objetivo, as mensagens de HELLO são enviadas periodicamente por todos os nós em modo broadcast e parâmetro time to live - TTL configurado com o valor igual a 1 (ou seja, com alcance máximo de 1 salto). Outra importante função das mensagens de HELLO, tem-se na participação da escolha dos nós MPR, do inglês Multipoint Relay. Portanto, as principais informações contidas em uma mensagem de HELLO são (CLAUSEN; JACQUET, 2003):

- Lista de endereços dos vizinhos a um salto.

- Tipo de enlace - indica para cada enlace do emissor do HELLO com um vizinho, se ele é simétrico, assimétrico ou se ficou indisponível. Um enlace simétrico significa que a comunicação foi estabelecida e confirmada em ambas as direções. Um enlace assimétrico indica que o emissor do HELLO é capaz de ouvir mensagens do vizinho, mas não sabe se suas mensagens são ouvidas por ele.

- Tipo de vizinho - indica se o vizinho possui pelo menos uma única conexão simétrica com a origem, ou ainda que o enlace é simétrico e selecionado como seu MPR (Multipoint Relay), ou é assimétrico ou indisponível.

- Campo Htime - especifica o intervalo de emissão desse tipo de mensagem.

Para redes com até três nós, as mensagens de HELLO são suficientes para divulgar as informações e possibilitar a convergência entre os nós. Porém, para redes com mais de três nós, as mensagens de TC do protocolo OLSR são necessárias para realizar essa tarefa. Basicamente uma mensagem de TC contém as seguintes informações:

- Campo ANSN (Advertised Neighbor Sequence Number) - indica o número de seqüência do anúncio. Toda vez que alguma mudança de topologia for detectada, esse número deve 
ser incrementado. Esse mecanismo permite que os demais nós saibam qual é a mensagem mais recente sobre a topologia da rede.

- Endereço do vizinho anunciado - contém o endereço principal de um nó vizinho. Nesse campo devem ser incluídos pelo menos, os endereços dos nós selecionados como MPRs do nó que gerou o pacote.

Periodicamente cada nó envia uma mensagem de TC em broadcast contendo uma lista de todos seus nós vizinhos. Ao receber uma mensagem de TC, somente os nós selecionados como MPRs são autorizados a repassar essa mensagem adiante, possibilitando assim sua propagação por toda rede. E assim, através das informações recebidas via mensagens de TC e HELLO, todos os nós participantes da rede, obtêm conhecimento suficiente para montar grafos representativos de toda topologia da rede.

A otimização que o protocolo OLSR trás para redes ad hoc deve-se principalmente em função do conceito de Multipoint Relay - MPR (CHLAMTAC, 2003). Este, por sua vez, tem como principal função a redução dos número de mensagens de broadcast (transmitidas pela rede durante o processo de atualização das rotas), como também a redução do tamanho dessas mensagens (BELDING-ROYER, 2003). A Figura 7 apresenta dois procedimentos de atualização das rotas em redes ad hoc.

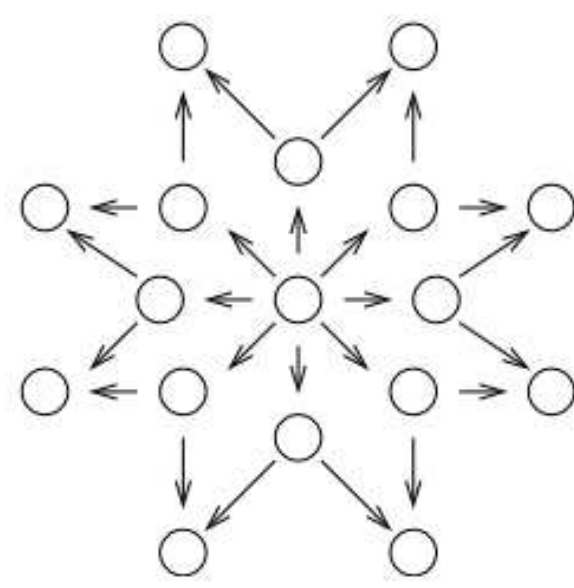

(a) Processo simples de broadcast

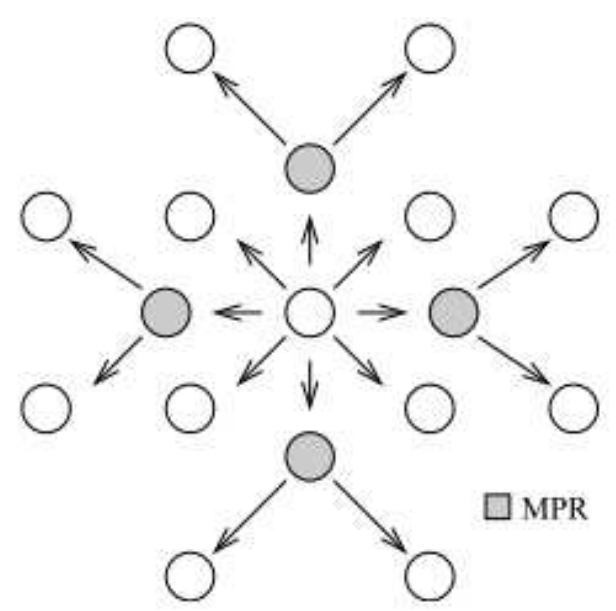

(b) Processo de broadcast utilizando MPR

Figura 7: Comparação entre processos de broadcast das mensagens de controle do protocolo.

Fonte: (RUBINSTEIN et al., 2006)

Utilizando o mecanismo MPR, como ilustrado na Figura 7(b), cada nó seleciona e armazena entre seus vizinhos a um salto, um grupo de nós responsável por retransmitir as mensagens de atualização da rede. Estes então, são conhecidos como nós MPR, sendo os únicos nós com 
capacidade de retransmitir mensagens. Dessa forma, a quantidade de mensagens trocadas pelos nó diminui drasticamente, quando comparado com um sistema simples de propagação das mensagens de broadcast (Figura 7(a)), pois apenas alguns nó escolhidos propagam as mensagens broadcast.

Cada nó da rede deve eleger entre seus vizinhos, nós MPRs para difundirem suas mensagens de TC. Com base nas informações fornecidas pelas mensagens de HELLO cada nó atualiza seu repositório de vizinhos a um salto (Conjunto de Vizinhos) e adquire conhecimento suficiente para: encontrar seus vizinhos a dois saltos e selecionar os nós MPR. Segundo o trecho resumido por (KAKITANI, 2010) da RFC 3626, a seleção dos nós MPR deve seguir a seguinte heurística:

1. Considerando-se xMPRref como o nó de referência que elegerá seus nós MPRs, Nx o conjunto de nós vizinhos a um salto do nó xMPRref e yNx como sendo um nó de Nx, é calculada a quantidade de vizinhos a um salto que cada nó yNx possui.

2. Os nós yNx que possuem vizinhos exclusivos, ou seja, vizinhos a dois saltos do nó xMPRref que nenhum outro nó yNx possui, são escolhidos como nós MPRs.

3. O cálculo da quantidade de vizinhos de cada nó yNx ainda não escolhido como MPR é então refeito desconsiderando os vizinhos que já foram cobertos pelos MPRs.

4. São escolhidos como MPRs os nós yNx que possuem o maior número de vizinhos a um salto ainda não coberto.

5. Os itens 3 e 4 são repetidos até que todos os nós vizinhos a dois saltos do nó xMPRref sejam cobertos pelos nós escolhidos como MPRs.

O conjunto de nós MPR resultante é representado pelo menor grupo de nós necessário para atingir os vizinhos a dois saltos. Todos os nós pertencentes à rede compartilham seus MPRs com seus vizinhos através das mensagens de HELLO. Ao receber uma mensagem de HELLO, cada nó grava os nós que o selecionaram como MPR. Estes nós são conhecidos como seletores de MPR. Sendo que qualquer mensagem de atualização transmitida por um determinado nó da rede somente carregará informações sobre seus seletores MPR. Portanto, o tamanho da mensagem de atualização pode ser reduzido e um determinado nó de destino na rede somente poderá ser atingido a partir de seus seletores MPR (RUBINSTEIN et al., 2006).

O Capítulo 2 trouxe uma breve descrição sobre alguns dos conceitos necessários para a melhor compreensão deste trabalho. A seguir no Capítulo 3, apresentam-se os detalhes da atual proposta, juntamente com os procedimentos necessários para sua implementação. 


\section{PROPOSTA}

Este trabalho propõe um modelo de roteamento, onde a troca de informações entre as camadas de acesso e de rede ajudam na escolha das melhores rotas. Neste caso, entende-se que as melhores rotas são aquelas que permitirão atingir os maiores valores de vazão média fim-a-fim.

O desempenho do modelo proposto será investigado por meio de simulações. Para que as simulações apresentem resultados confiáveis, é necessário que a camada física reflita da maneira mais realística possível, as mudanças que o canal de transmissão sem fio possa sofrer. Seguindo essa premissa, a camada de rede precisa estar preparada para tratar as informações obtidas na camada de acesso e utilizá-las para realizar o cálculo otimizado das rotas.

Com esse intuito, escolheu-se utilizar o protocolo OLSR para realizar a escolha otimizada da rota e divulgação dessa informação entre os outros nós pertencentes à rede. O protocolo OLSR, como descrito na RFC3626, faz a escolha da rota para o destino buscando a rota que irá proporcionar o menor número de saltos. Já na atual proposta essa métrica será modificada, de forma que o algoritmo deverá escolher o caminho que irá proporcionar a maior vazão possível no percurso fim-a-fim.

Portanto, a partir das mensagens de HELLO (OLSR) trocadas entre os elementos da rede e seus vizinhos a 1 salto, a camada de acesso calcula o valor da relação sinal ruído mais interferência (SINR) correspondente ao enlace em questão. Dessa maneira todos os elementos pertencentes à topologia adquirem conhecimento do estado (SINR) do enlace com seus vizinhos. E para que os elementos mais distantes também tenham esse conhecimento, essa informação é incluída na mensagem de TC e no repositório do protocolo OLSR respectivo. Assim, conhecendo o valor de SINR, a camada de rede determina qual a taxa de transmissão e respectiva modulação que irá proporcionar a maior vazão possível no enlace em questão. Por fim, de posse dessas duas últimas informações (SINR e modo de transmissão) o elemento associa um custo ao enlace. Este custo caracteriza uma nova métrica para o protocolo, definido como a máxima vazão teórica possível de ser atingida no mesmo. Mais detalhes sobre esse processo, serão discutidos na subseção 3.1 (Implementação da Proposta) a seguir. 
Este trabalho também propõe o uso do padrão $802.11 \mathrm{~g}$, que por sua vez conta com 8 taxas de transmissão - 6Mbps à 54Mbps. O padrão 802.11 deixa livre para cada fabricante a definição de um algoritmo para a seleção das taxas de transmissão. Essa escolha deve levar em conta as condições do canal, que podem variar de forma significativa ao longo do tempo. De modo que, quanto mais baixa a taxa de transmissão, mais robusta é a transmissão feita usando essa taxa. Assim em uma situação ideal, a adaptação da taxa consistiria em diminuir a taxa quando a qualidade do canal piorasse e aumentar quando a mesma melhorasse, sendo a qualidade mapeada na SINR percebida no receptor (CARDOSO; REZENDE, 2008).

Várias formas de adaptar a taxa de transmissão à condição do canal já foram propostas (HOLLAND; VAIDYA; BAHL, 2001) (LACAGE et al., 2004) (KIM; KIM; CHOI, 2006). No esquema conhecido como Receiver-Based AutoRate - RBAR (HOLLAND; VAIDYA; BAHL, 2001), através da troca de mensagens de Request to Send - RTS e Clear to Send - CTS, é possível que o transmissor conheça o estado (SINR) no receptor e adapte a sua taxa de transmissão de acordo. É com base nesse esquema, que surge a inspiração para o modelo de adaptação de taxa proposto nesse trabalho. No entanto, o trabalho atual tem por convenção não utilizar as mensagens de RTS/CTS, já que as mesmas não proporcionam uma melhora significativa no desempenho do sistema (XU; GERLA; BAE, 2003) (JOHNSON; AICHELE; NTLATLAPA, 2008). Assim, ao invés de utilizar mensagens de RTS/CTS para que a origem conheça o valor de SINR no destino, no modelo proposto as mensagens de controle do protocolo OLSR serão aproveitadas para o mesmo fim.

Assim, de acordo com o valor de SINR calculado no receptor, o algoritmo irá escolher a forma de transmissão que irá proporcionar a maior vazão teórica possível. Portanto, além deste modelo promover a escolha do caminho que possibilitará atingir a maior vazão possível, os elementos sem fio também irão adaptar as suas taxas de transmissão de acordo com o estado do enlace (ponto-a-ponto), na tentativa de atingir essa mesma máxima vazão teórica.

Para fins de comparação e verificação de desempenho, também é objetivo dessa proposta a simulação de cenários que implementem a combinação do modelo proposto, com as vantagens proporcionadas pelos esquemas que fazem uso de múltiplas antenas. Por simplicidade, no estudo de esquemas MIMO consideramos somente casos onde tanto o transmissor quanto o receptor possuem duas antenas, de modo que avaliamos o desempenho dos esquemas bastante conhecidos (GOLDSMITH, 2005): Beamforming 2x2, Alamouti 2x2, e V-BLAST 2x2. Vale ressaltar que tanto no caso de Beamforming quanto do uso da técnica de Alamouti, supomos que o receptor faz a combinação por razão máxima (MRC).

A seguir, na seção 3.1, temos uma descrição mais detalhada do processo de implementação 
da proposta.

\subsection{IMPLEMENTAÇÃO DA PROPOSTA}

A fim de implementar a atual proposta, escolheu-se utilizar a versão 2.34 do Network Simulator - NS (THE..., 2010). O NS é um simulador de eventos discretos de código aberto, desenvolvido para pesquisa em redes (ISSARIYAKUL; HOSSAIN, 2008). A versão padrão do NS não possui suporte à simulação das diferentes taxas de transmissão especificadas pelos padrões 802.11 b e 802.11 g. Como a atual proposta exige um sistema onde os nós possuam tal capacidade, o NS foi alterado para atingir tal propósito. Para isso, substitui-se a camadas de acesso pela biblioteca conhecida como dei80211 mr, incluída no pacote all-in-one do NS. A biblioteca dei80211 mr fornece uma nova implementação do padrão IEEE 802.11 para o NS. Além de possibilitar a simulação de diferentes taxas de transmissão, definidas pelos padrões 802.11 b e $802.11 \mathrm{~g}$, também acrescenta outras funcionalidades. Dentre elas podemos destacar a inclusão de um modelo de nível de erro de pacotes, baseado no valor da relação sinal interferência mais ruído, do inglês Signal-to-Interference Noise Ratio - SINR. Com isso, as perdas de pacotes passam a ser determinadas pela taxa de pacotes perdidos, do inglês Packet Error Rate - PER, não mais pela variável Rx Threshold utilizada na versão padrão do NS. Os valores de PER são fornecidos como parâmetros de entrada a partir de curvas PER vs. SINR e tamanho de pacote pré-calculadas. Isso permite a simulação de um cenário mais realístico, tendo em vista que o NS padrão não leva em conta o ruído e interferência na recepção do sinal. Ele somente verifica se a potência do sinal recebido é maior que um determinado valor limiar, caso sim, considera-se que a informação foi recebida com sucesso. Para determinar o valor de SINR, a interferência é calculada utilizando um modelo Gaussiano, capaz de levar em consideração o efeito das transmissões simultâneas no receptor. A equação correspondente (incluída pela biblioteca dei80211 $\mathrm{mr}$ do simulador NS 2.34) é representada por:

$$
\operatorname{SINR}=\frac{P_{r}}{N+I}
$$

onde $P_{r}$ é a potência recebida, $N$ é a potência do ruído na recepção e $I$ é a potência de interferência percebida no receptor em função das transmissões simultâneas na rede. O modelo de desvanecimento em larga escala utilizado é o de propagação no espaço livre (RAPPAPORT, 2002). Além das alterações até aqui citadas, a biblioteca também corrige alguns problemas conhecidos do NS, envolvendo o tempo randômico de backoff, modelo de captura e negação de acesso direto.

A versão original do NS não tem capacidade de simular cenários utilizando as vantagens 
proporcionadas pelos esquemas MIMO. Buscando então cumprir com os objetivos da atual proposta, capturou-se os valores de FER para um faixa de valores da relação sinal ruído, do inglês Signal-to-Noise Ratio - SNR, considerando o modelo de desvanecimento Rayleigh. E para tal, convencionou-se utilizar o conceito de probabilidade de outage. Para a realização dos cálculos descritos neste trabalho e representação de seus resultados na forma de figuras, escolheu-se utilizar o auxílio do programa computacional: MATLAB. Além de prover um ambiente interativo de desenvolvimento, o MATLAB é também uma linguagem de programação de alto nível, capaz de realizar computações numéricas, análise e visualização de dados (MATHWORKS, 2007).

Como foi introduzido no capítulo de conceitos (Capítulo 2 - Seção 2.2), a probabilidade de outage é capaz de "prever"de forma bastante verossímil a taxa de erro de quadro (FER) de códigos práticos com tamanho de bloco relativamente curtos. Assim, para efeitos desse estudo, considerou-se que os valores de $P_{\text {out }}$ (obtidos ao aplicar as equações introduzidas na Seção 2.2 na ferramenta MATLAB) são iguais à FER. E deste modo, FER é utilizada como parâmetro de entrada para o código do NS, a fim de simular o modelo de perdas e, consequentemente, o comportamento de cenários distintos do ponto de vista da camada de acesso.

Como este trabalho propõe o uso do padrão $802.11 \mathrm{~g}$, iremos considerar nas simulações as oito taxas de transmissão compreendidas pelo padrão. Portanto, isolando $\gamma_{\min }$ em (6) e substituindo o mesmo em (8), a equação resultante (9) possibilita obter o valor da probabilidade de outage para as oito taxas do padrão 802.11g. Nessa mesma equação as taxas (802.11g) são substituídas na variável $C$ e os valores SINR na variável $\bar{\gamma}_{s}$ (considerando interferência nula). Os resultados obtidos estão dispostos na Figura 8, a qual representa um sistema SISO, do inglês Simple Input Simple Output, ou seja, composto por uma única antena transmissora e uma única antena receptora.

Buscando explorar o comportamento de outros cenários que implementem esquemas MIMO distintos, também se obteve os valores de $P_{\text {out }}$ para as seguintes esquemas: Beamforming $2 \times 2$, Alamouti 2x2 e V-BLAST 2x2. Como o Beamforming 2x2 é equivalente a um esquema com MRC no transmissor e receptor (GOLDSMITH, 2005), este apresenta as mesmas curvas de $P_{\text {out }}$ de um esquema MRC 1x4. Portanto, com auxílio de (10) e da ferramenta MATLAB, a Figura 9 apresenta os valores de $P_{\text {out }}$ em um sistema de comunicação que utiliza Beamforming 2x2. Mais uma vez, os resultados foram obtidos para as oito taxas do padrão $802.11 \mathrm{~g}$.

Para obter os valores de $P_{\text {out }}$ considerando o esquema Alamouti 2x2, utilizou-se um processo semelhante ao caso com Beamforming $2 \times 2$. Mais uma vez os valores de $P_{\text {out }}$ foram obtidos considerando a equação para MRC $1 \times 4$, porém o valor da SNR média medida no receptor 


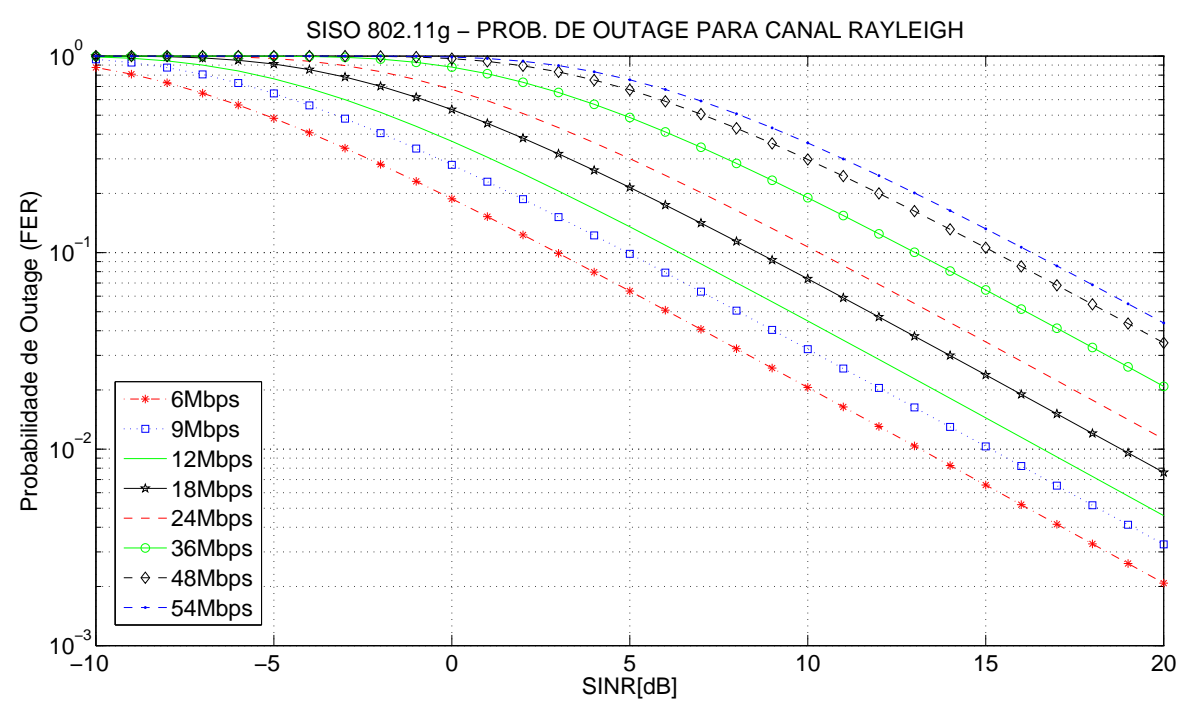

Figura 8: SISO - Valores de $P_{\text {out }}$ para as oito taxas do padrão IEEE 802.11g.

Fonte: Autoria própria

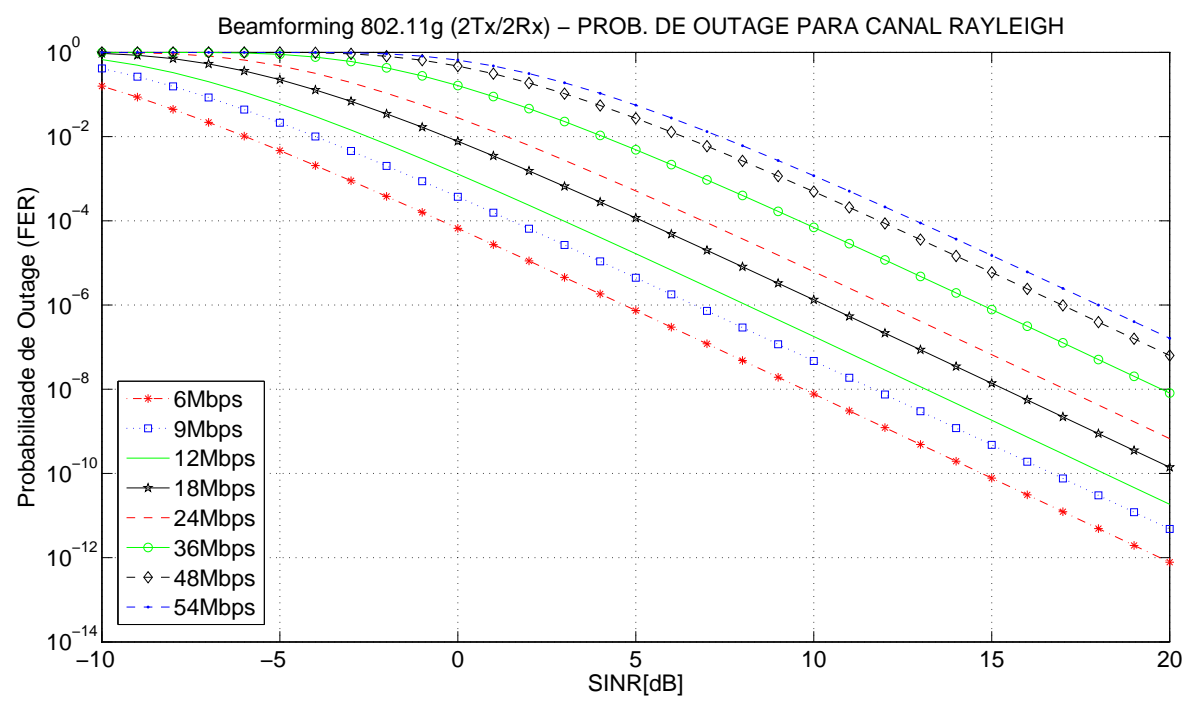

Figura 9: Beamforming 2x2 - Valores de $P_{\text {out }}$ para as oito taxas do padrão IEEE $802.11 \mathrm{~g}$.

\section{Fonte: Autoria própria}

é a metade. Tal artifício matemático se justifica pelo fato de considerarmos que potência total transmitida pelas duas antenas no esquema Alamouti (ALAMOUTI, 1998), ser igual a potência utilizada para transmitir por uma única antena no caso com MRC. A Figura 10 apresenta as curvas de $P_{\text {out }}$ para o esquema Alamouti 2x2 (GOLDSMITH, 2005).

Por fim, buscando explorar o comportamento de sistemas que implementem o esquema V-BLAST 2x2, a Figura 11 apresenta os valores de $P_{\text {out }}$ obtidos com auxílio de (11). 


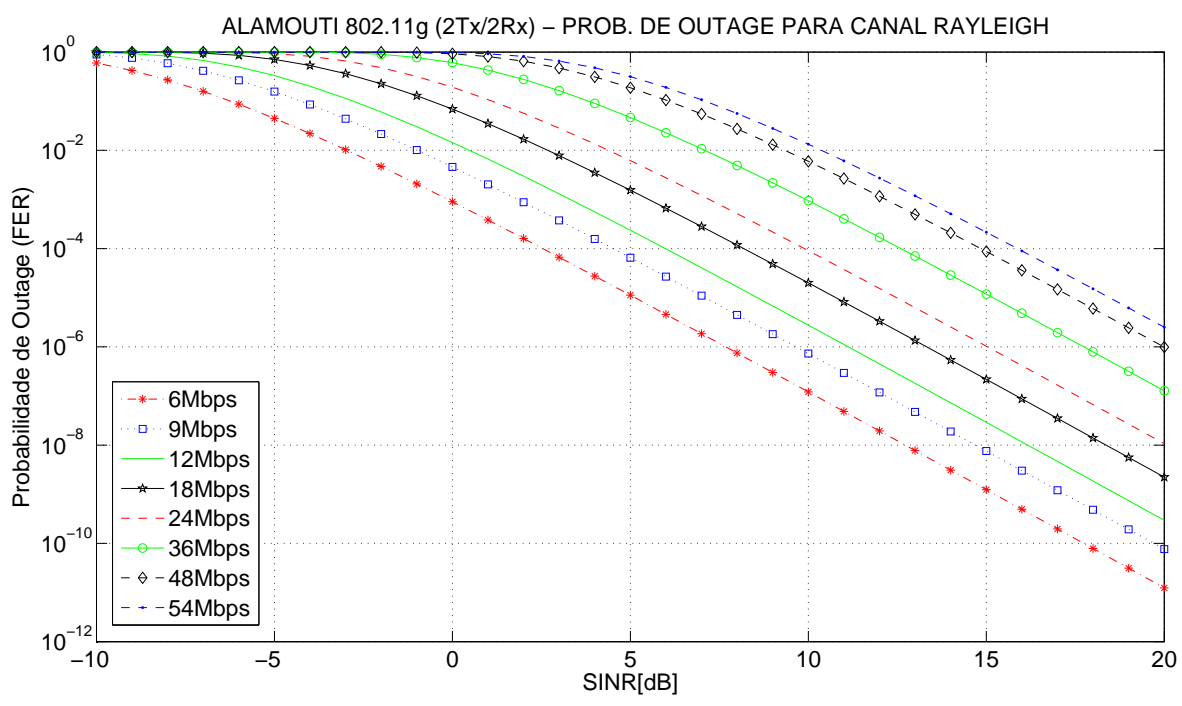

Figura 10: Alamouti 2x2 - Valores de $P_{\text {out }}$ para as oito taxas do padrão IEEE 802.11g.

Fonte: Autoria própria

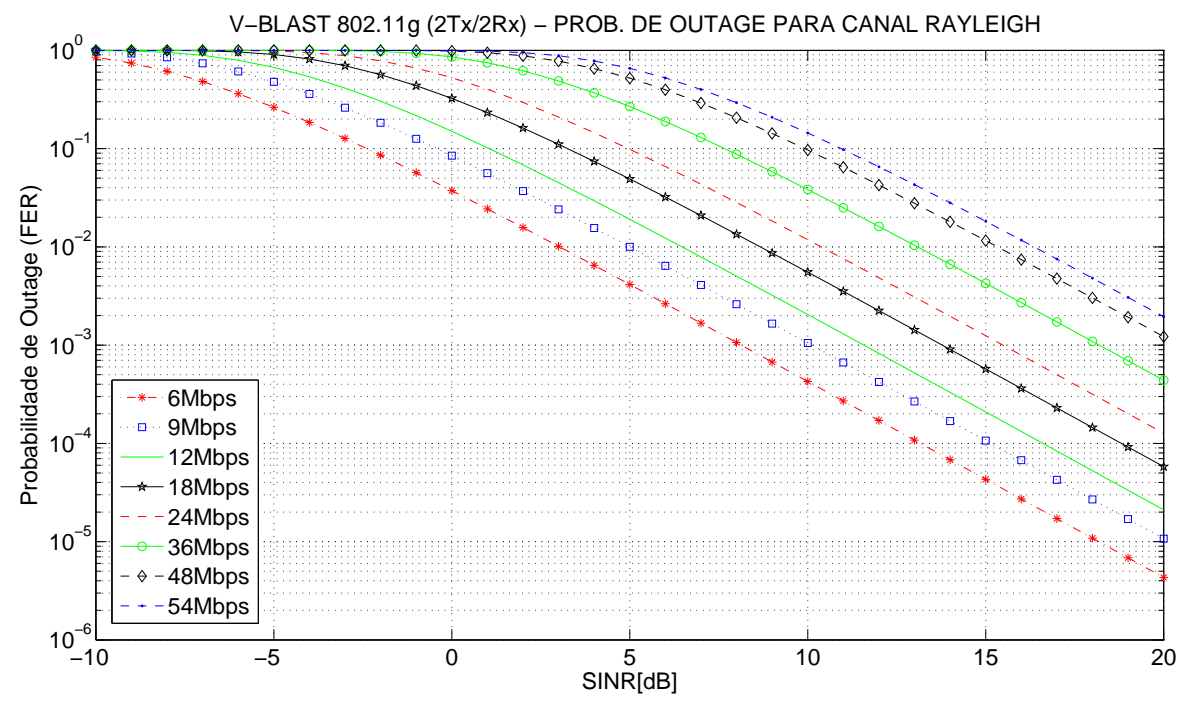

Figura 11: V-BLAST 2x2 - Valores de $P_{\text {out }}$ para as oito taxas do padrão IEEE $802.11 \mathrm{~g}$.

\section{Fonte: Autoria própria}

A seguir, para cumprir com os objetivos do modelo proposto, a subseção 3.1.1 apresenta com mais detalhes as modificações necessárias na métrica do protocolo de roteamento OLSR e o modelo de transmissão adaptativo. 


\subsubsection{MÉTRICA OLSR E O MODELO DE TRANSMISSÃO ADAPTATIVO}

Até agora a implementação foi discutida do ponto de vista da camada de acesso à rede. Porém, para atingir os objetivos dessa proposta, grande parte das alterações necessárias foram implementadas na camada de rede. Para começar a versão padrão do NS não suporta o protocolo de roteamento OLSR. Com o objetivo de incluí-lo no NS, utilizou-se a extensão conhecida como UM-OLSR, disponível em (ROS, 2009). A extensão UM-OLSR trata-se de uma implementação do protocolo de roteamento OLSR para o NS, que segue as recomendações da RFC3626.

Este trabalho propõe uma nova métrica para o OLSR. Ao invés de buscar o caminho com menor número de saltos, como é determinado pelo OLSR padrão, o OLSR modificado irá buscar o caminho que permitirá atingir a maior vazão possível no percurso fim-a-fim. Com esse objetivo, quando uma mensagem de HELLO é recebida por um determinado nó da rede, este último calcula a relação sinal ruído mais interferência (SINR). Tal informação representa o estado do enlace sem fio e é adicionada na mensagem de TC e repositório do protocolo OLSR respectivo, para posterior divulgação entre os elementos da rede. Por fim, conhecendo o valor de SINR, a camada de rede determina qual a taxa de transmissão e respectiva modulação que irá proporcionar a maior vazão possível no enlace respectivo. Com esse intuito, foram obtidas as curvas de vazão $\mathscr{V}$ para cada taxa de transmissão do padrão IEEE 802.11g, de acordo com:

$$
\mathscr{V}=R \times\left(1-P_{\text {out }}\right)
$$

de forma que o parâmetro $P_{\text {out }}$ representa a probabilidade de outage e a variável $R$ representa as taxas de transmissão do padrão 802.11g. E assim a Figura 12 apresenta a evolução dessas curvas de vazão, considerando uma faixa de valores de SINR.

Com base nas informações encontradas na Figura 12, montou-se uma tabela que relaciona as taxas de transmissão que proporcionarão a maior vazão possível para intervalos distintos de valores de SINR. A Tabela 2 ilustra essa relação, considerando um sistema que não conta com o auxílio de esquemas MIMO (SISO).

Assim, de acordo com valor de SINR calculado ao receber a mensagem de HELLO, a camada de rede consulta as informações dispostas na Tabela 2 e obtém qual a taxa de transmissão que irá proporcionar a maior vazão possível no enlace sem fio respectivo. E por fim, conhecendo esses dois parâmetros o elemento irá determinar e associar um custo ao enlace em questão. Este custo representa e define uma nova métrica para o protocolo OLSR, caracterizado como a máxima vazão teórica possível de ser atingida nesse enlace. Tal valor foi obtido a partir das informações apresentadas na Figura 12. 


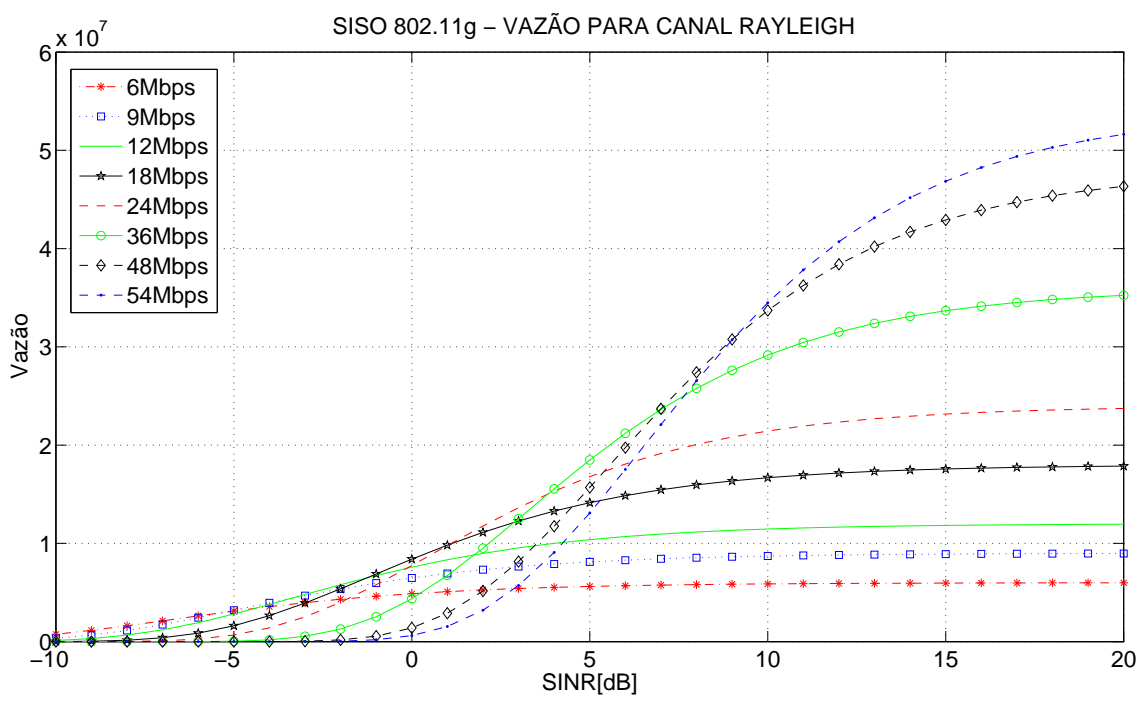

Figura 12: SISO - Curvas de Vazão para as oito taxas do padrão IEEE 802.11g.

Fonte: Autoria própria

Tabela 2: Faixas de SINR e respectiva taxa de transmissão capaz de proporcionar a maior vazão possível para o enlace

\begin{tabular}{cc}
\hline Faixas de SINR & Taxa de Transmissão \\
\hline \hline$-10 \mathrm{~dB} \rightarrow-5.25 \mathrm{~dB}$ & $6 \mathrm{Mbps}$ \\
$-5.25 \mathrm{~dB} \rightarrow-3.42 \mathrm{~dB}$ & $9 \mathrm{Mbps}$ \\
$-3.42 \mathrm{~dB} \rightarrow-1.25 \mathrm{~dB}$ & $12 \mathrm{Mbps}$ \\
$-1.25 \mathrm{~dB} \rightarrow 1 \mathrm{~dB}$ & $18 \mathrm{Mbps}$ \\
$1 \mathrm{~dB} \rightarrow 3.38 \mathrm{~dB}$ & $24 \mathrm{Mbps}$ \\
$3.38 \mathrm{~dB} \rightarrow 6.95 \mathrm{~dB}$ & $36 \mathrm{Mbps}$ \\
$6.95 \mathrm{~dB} \rightarrow 9.04 \mathrm{~dB}$ & $48 \mathrm{Mbps}$ \\
$9.04 \mathrm{~dB} \rightarrow \infty$ & $54 \mathrm{Mbps}$ \\
\hline
\end{tabular}

Fonte: Autoria própria

A fim de implementar as alterações referentes a métrica do protocolo discutidas nessa subseção, o NS também foi modificado para obter os valores de vazão, através de uma tabela de texto externa. Essa tabela por sua vez, resume as informações representadas pela Figura 12. Assim, utilizando o valor de SINR calculado para mensagem de HELLO e a taxa de transmissão escolhida (utilizando a Tabela 2) como parâmetros de entrada, o código busca na tabela de texto externa o valor de vazão respectivo associado ao enlace. Este valor é o custo $\mathscr{C}$, ou seja, é métrica sugerida para o OLSR proposto. Porém, buscando a simplificação no cálculo dessa métrica fim-a-fim, escolheu-se utilizar uma métrica aditiva (WANG; CROWCROFT, 1996), no caso a inversa da vazão, como exposto pela equação:

$$
\mathscr{C}=\sum_{i} \frac{1}{\mathscr{V}_{i}}
$$


onde $i$ representa o número de saltos. Dessa forma, basta somar o valor deste custo a cada salto entre origem e destino, para se obter o valor do custo fim-a-fim. Ao utilizar a nova métrica proposta, uma determinada rota mesmo apresentando número de saltos superior, poderá ser escolhida como melhor caminho caso possibilite atingir um maior valor de vazão média no percurso fim-a-fim.

Com o intuito de atingir essa mesma máxima vazão teórica, além deste modelo promover a escolha do caminho que possibilitará atingir a maior vazão possível, os elementos sem fio também irão adaptar as suas taxas de transmissão de acordo com o estado do enlace. Para isso, dependendo do estado (SINR) do enlace no receptor, o elemento irá buscar na Tabela 2 a taxa respectiva e utilizar a mesma no enlace em questão.

E buscando simular outros cenários de rede que incluam o uso de esquemas MIMO, utilizouse um processo análogo ao utilizado para simular o cenário com única antena transmissora e receptora (SISO). Com esse objetivo, obteve-se os valores de vazão para um cenário com a técnica Beamforming 2x2. Para tal simplesmente substituiu-se (10) em (13), considerando $M=4$. Já para obter os valores de vazão em sistemas que implementem a técnica Alamouti 2x2, o processo é semelhante ao utilizado em um sistema com Beamforming $2 \times 2$ (ou MRC 1x4). Entretanto, como se assumiu que a potência total transmitida pelas duas antenas no esquema Alamouti é igual a potência transmitida pela única antena no esquema MRC 1x4, um artifício matemático teve que ser incluído para refletir essa configuração. Tal artifício corresponde a simples redução da SNR média medida no receptor à metade. Assim, obteve-se os valores de vazão para um sistema Alamouti com duas antenas receptoras. A Figuras 13 e 14 apresentam as curvas de vazão obtidas para cada uma das oitos taxas de transmissão do padrão $802.11 \mathrm{~g}$, utilizando os esquemas MIMO Beamforming 2x2 e Alamouti 2x2, respectivamente.

E por final, buscando simular o comportamento de cenários que implementem o esquema MIMO conhecido como V-BLAST, primeiramente substituiu-se (11) em (13). A equação resultante foi acrescida de um artifício matemático (multiplicada por 2), já que o uso técnica V-BLAST duplica a vazão dos dados transmitidos (GOLDSMITH, 2005). As curvas de vazão obtidas estão representadas na Figura 15. As tabelas utilizadas para relacionar as taxas de transmissão que proporcionarão a maior vazão possível para intervalos distintos de valores de SINR (considerando os esquemas MIMO: Alamouti 2x2, VBLAST 2x2 e Beamforming 2x2), estão dispostas no Apêndice A.

A seguir, na Subseção 3.1.2, apresentam-se com mais detalhes os mecanismos envolvidos na propagação da nova métrica proposta, sendo esta realizada por mensagens específicas do protocolo de roteamento OLSR. 


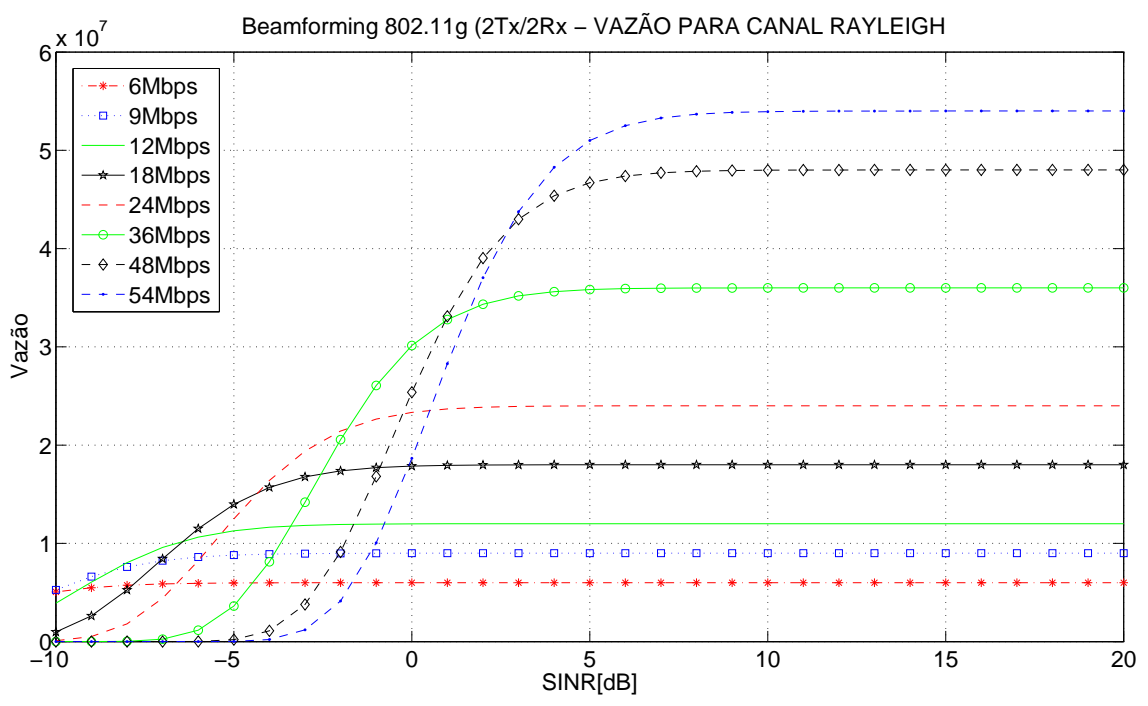

Figura 13: Beamforming 2x2 - Curvas de Vazão para as oito taxas do padrão IEEE 802.11g. Fonte: Autoria própria

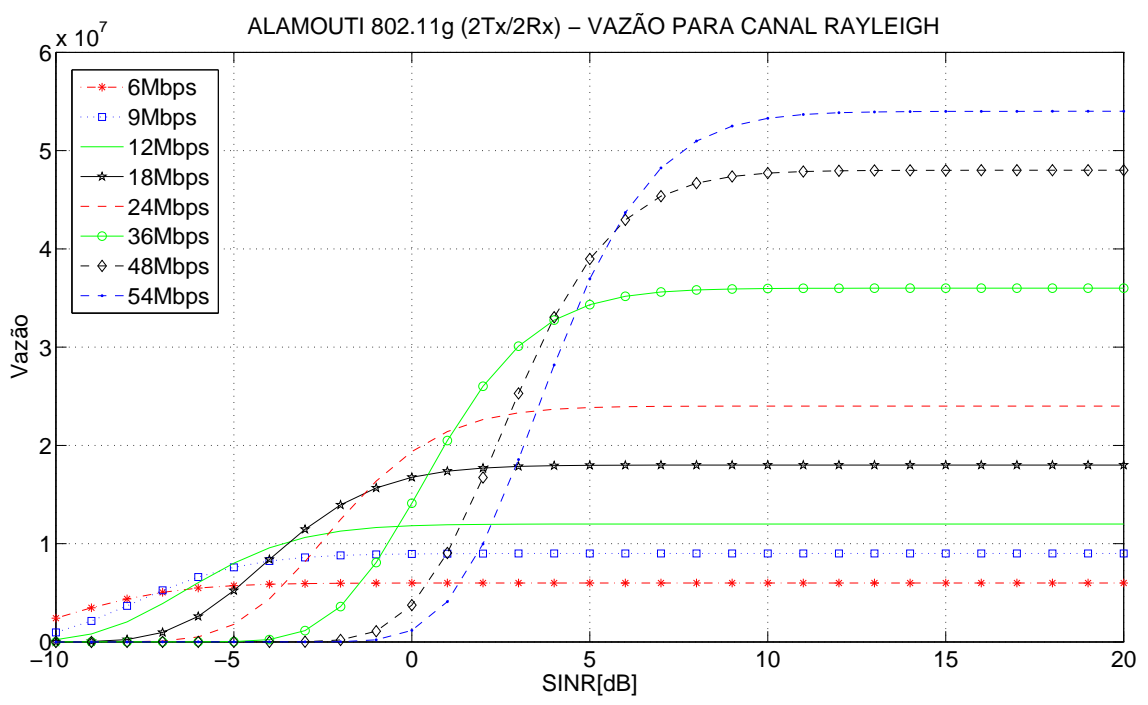

Figura 14: Alamouti 2x2 - Curvas de Vazão para as oito taxas do padrão IEEE 802.11g.

Fonte: Autoria própria

\subsubsection{PROTOCOLO OLSR - PROPAGAÇÃO DA NOVA MÉTRICA}

O uso da nova métrica proposta exige que cada nó pertencente a topologia, tenha conhecimento prévio das faixas de SINR e a taxa de transmissão respectiva que irão proporcionar a maior vazão possível. E da mesma forma, as estruturas de armazenamento do protocolo deverão ser modificadas, de maneira que elas também armazenem e utilizem o valor de SINR e a nova métrica definida. Assim, com base nessas novas informações disponíveis nas estruturas de 


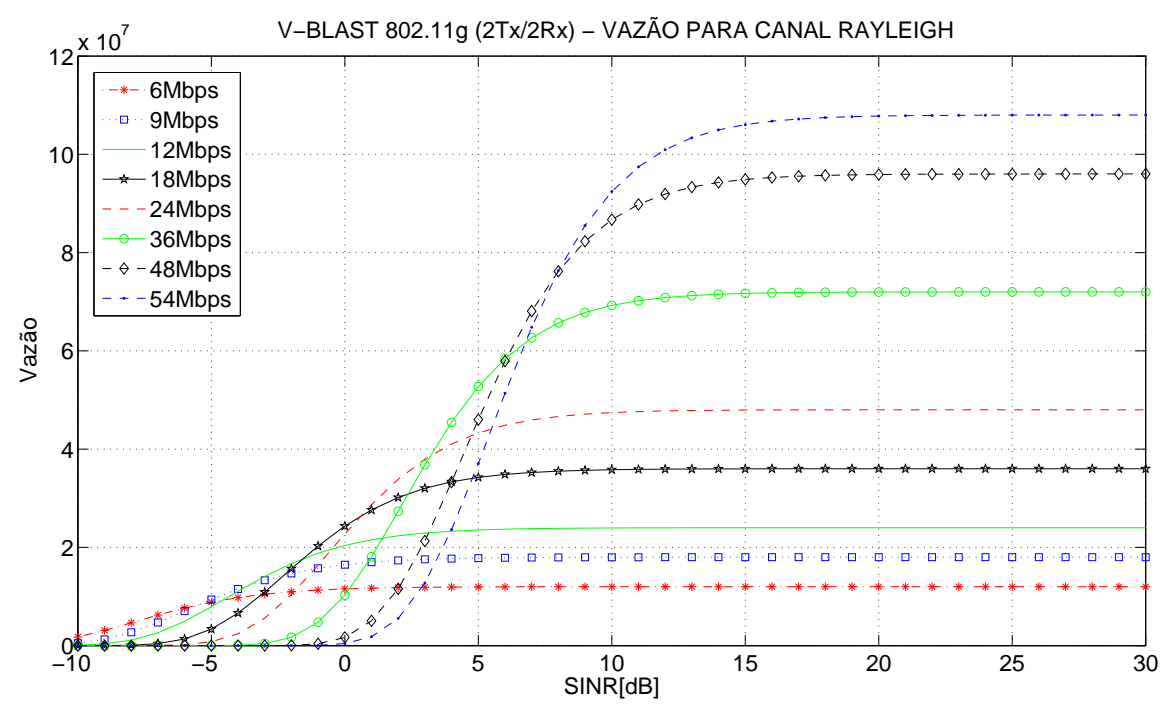

Figura 15: V-BLAST 2x2 - Curvas de Vazão para as oito taxas do padrão IEEE 802.11g.

Fonte: Autoria própria

armazenamento do protocolo, o algoritmo de roteamento deverá determinar o melhor caminho para todos os destinos da rede. Sendo este então, o caminho que apresentar a maior vazão possível no percurso fim-a-fim. E ao descobrir o melhor caminho, a tabela de roteamento deverá ser atualizada e essas novas informações deverão ser distribuídas entre os outros elementos da rede. Para divulgar os valores da nova métrica entre os nós da rede, as mensagens de HELLO e TC tiveram que ser modificadas, de modo a incluir o valor desse custo no cabeçalho da mensagem. A Figura 16 apresenta essa alteração na mensagem de HELLO, como também sua propagação entre os nós da rede.

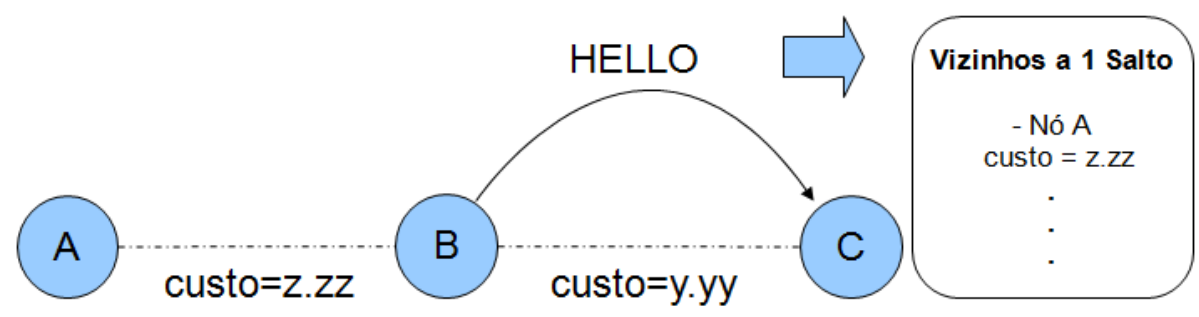

Figura 16: Propagação da mensagem de HELLO

\section{Fonte: Autoria Própria}

Como pode ser observado na Figura 16, o nó B envia mensagens de HELLO em modo broadcast para seus nós vizinhos. No caso, evidencia-se somente a mensagem de HELLO enviada para o nó $\mathrm{C}$, já que a mensagem enviada para o nó A realiza um processo análogo. Essa mensagem inclui o custo do enlace A-B, que ele busca de sua estrutura de vizinhos a um salto. Sendo assim o nó $\mathrm{C}$ toma conhecimento da presença do nó A, e o adiciona em sua estrutura de vizinhos 
a dois saltos. Junto a nova entrada na estrutura, anexa-se o valor do custo fim-a-fim, este obtido pela soma dos custos entre os enlaces C-B e B-A.

Da mesma maneira que as mensagens de HELLO foram modificadas na implementação atual, as mensagens de TC também foram alteradas para manter com os objetivos da proposta. Então, adicionou-se o valor do custo no seu cabeçalho, de maneira que a troca de mensagens de TC pode ser representada pela Figura 17.

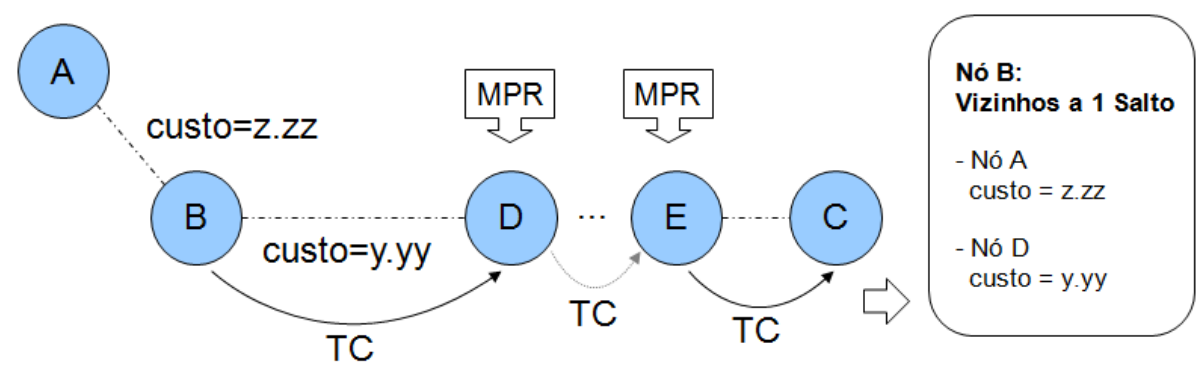

Figura 17: Propagação da mensagem de TC

Fonte: Autoria Própria

Ao enviar a mensagem de TC, o nó B deve incluir a identificação dos seus vizinhos e o valor respectivo do custo no enlace para atingir os mesmos. Assim o nó B envia em sua mensagem de TC a identificação de seus nós vizinhos, A e C, e o respectivo valor do custo no enlace entre eles. Essa mensagem de TC é recebida pelo nó D, sendo este o nó MPR escolhido pelo nó B. Este então, retransmite a mensagem de TC adiante, que por sua vez é retransmitida por outros nós MPRs até atingir o nó $\mathrm{E}$ (escolhido como MPR pelo nó C). Ao receber a mensagem de TC, o nó $\mathrm{C}$, além de adquirir conhecimento sobre a existência dos nós mais distantes da rede (acima de três saltos), também conhecerá valor do custo fim-a-fim para atingir os mesmos.

Também é importante comentar que, por convenção, todas as mensagens de sinalização serão enviadas com taxa de transmissão igual a 6 Mbps. Assim, temos um aumento na probabilidade de entrega das mesmas, garantindo que os nós da rede obtenham um conhecimento instantâneo mais atualizado da situação real do meio.

No OLSR, como descrito pela RFC3626, quando um nó for atualizar sua tabela de roteamento, inicialmente ele irá remover todas as entradas que lá existirem e adicionar todos os nós vizinhos a um salto. Na sequência, ele adiciona todos os nós vizinhos a dois saltos, tendo como próximo salto a partir da origem, o nó vizinho a um salto adicionado no passo anterior. Já para os nós a três ou mais saltos, adicionam-se as entradas correspondentes encontradas no Repositório de Informações de Topologia, sempre buscando o menor número de saltos possível para atingir o destino. 
A proposta atual mantém um procedimento de atualização da tabela de roteamento muito semelhante ao do OLSR padrão. Porém ainda assim, algumas alterações foram necessárias já que a mesma não utiliza o número de saltos como métrica, e sim o menor custo na propagação dos dados entre origem e destino.

Primeiramente, antes de adicionar os vizinhos a dois saltos na tabela de roteamento, o algoritmo irá verificar se o nó encontrado a dois saltos é também vizinho a um salto. Para isso, busca na tabela de roteamento se o mesmo já foi adicionado (como destino a um salto) no passo anterior. Caso sim, ele verifica se o valor do custo para atingí-lo a dois saltos, é menor que o custo para atingí-lo diretamente em um salto. Se for menor, ele remove a entrada da tabela de roteamento e adiciona o novo caminho para o mesmo utilizando os dois saltos. Já se o custo com dois saltos for maior, ele mantém a entrada que foi adicionada anteriormente.

Uma segunda alteração, necessária e implementada aqui para manter o algoritmo condizente com os objetivos da proposta, têm-se quando o nó encontra um segundo caminho a dois saltos para um mesmo destino. O OLSR padrão mantém a entrada antiga. Já a implementação atual verifica se o novo caminho possui um menor custo, caso sim, o algoritmo remove a entrada antiga e adiciona o caminho novo na tabela de roteamento. 


\section{AVALIAÇÃO DA PROPOSTA}

Buscando explorar e analisar o impacto gerado pela aplicação do modelo proposto, este capítulo apresentará a simulação de alguns cenários distintos e resultados respectivos. Em todas as simulações, considerou-se o uso do padrão $802.11 \mathrm{~g}$ e o modelo Rayleigh para canal de comunicação e desvanecimento (pequena escala). O modelo de desvanecimento em larga escala utilizado é o de propagação no espaço livre.

Para demonstrar de forma mais clara o desempenho do modelo proposto, definiu-se um modelo de referência para fins de comparação. Nesse contexto, foram capturados os resultados utilizando o protocolo OLSR como proposto pela RFC3626, ou seja, considerando o menor número de saltos como métrica. Nesse mesmo ambiente o mecanismo conhecido como AutoRate Fallback - ARF (KAMERMAN; MONTEBAN, 1997) foi selecionado para adaptar as taxas de transmissão de acordo com o estado do meio. Este foi selecionado pois alguns trabalhos da literatura afirmam que esse algoritmo, ou variantes do mesmo, são amplamente utilizados em equipamentos comerciais (KIM; KIM; CHOI, 2006) (SADEGHI et al., 2005) (KIM; LEE; CHOI, 2006).

De acordo com a proposta, este modelo deverá apresentar melhor desempenho principalmente em situações onde a rota selecionada (mesmo apresentando maior número de saltos), possibilitar atingir valores superiores de vazão fim-a-fim quando comparada com a rota selecionada pelo OLSR-RFC3626 (com piores condições de canal). Entretanto, em situações onde existir somente um enlace direto (ponto-a-ponto), o OLSR definido pela RFC3626 deverá apresentar desempenho similar.

Inicialmente se propôs um cenário mais simples e didático, com intuito de demonstrar de forma mais clara o desempenho do modelo proposto. Na sequência diversas topologias são apresentadas, combinando o uso modelo proposto com esquemas MIMO. 


\subsection{CENÁRIO DE SIMULAÇÃO 1}

Inicialmente propomos um cenário simplificado, com o intuito de apresentar de uma forma mais clara o impacto da aplicação do modelo proposto. Seguindo essa premissa, propôs-se um cenário formado por 11 nós sem fio dispostos como ilustrado na Figura 18, cujo o estado dos enlaces é representado pelo valor de SINR. Neste cenário um único fluxo com taxa de transmissão constante de 4Mbps e tamanho de pacote fixo em 1024 bytes, é gerado pelo nó 0 tendo o nó 5 como destino. Estes são representados pelo nó em formato de quadrado e o nó em formato de " $X$ " respectivamente. A potência de transmissão de cada elemento é fixada em 0,0361 Watts. Inicialmente durante um período de 15 segundos, os nós trocam pacotes de HELLO e TC entre si. Tal procedimento permite que os nós preencham seus repositórios com informação suficiente, de maneira que todos tenham conhecimento sobre a localização e condição do enlace fim-a-fim, de todos os outros nós pertencentes a topologia.

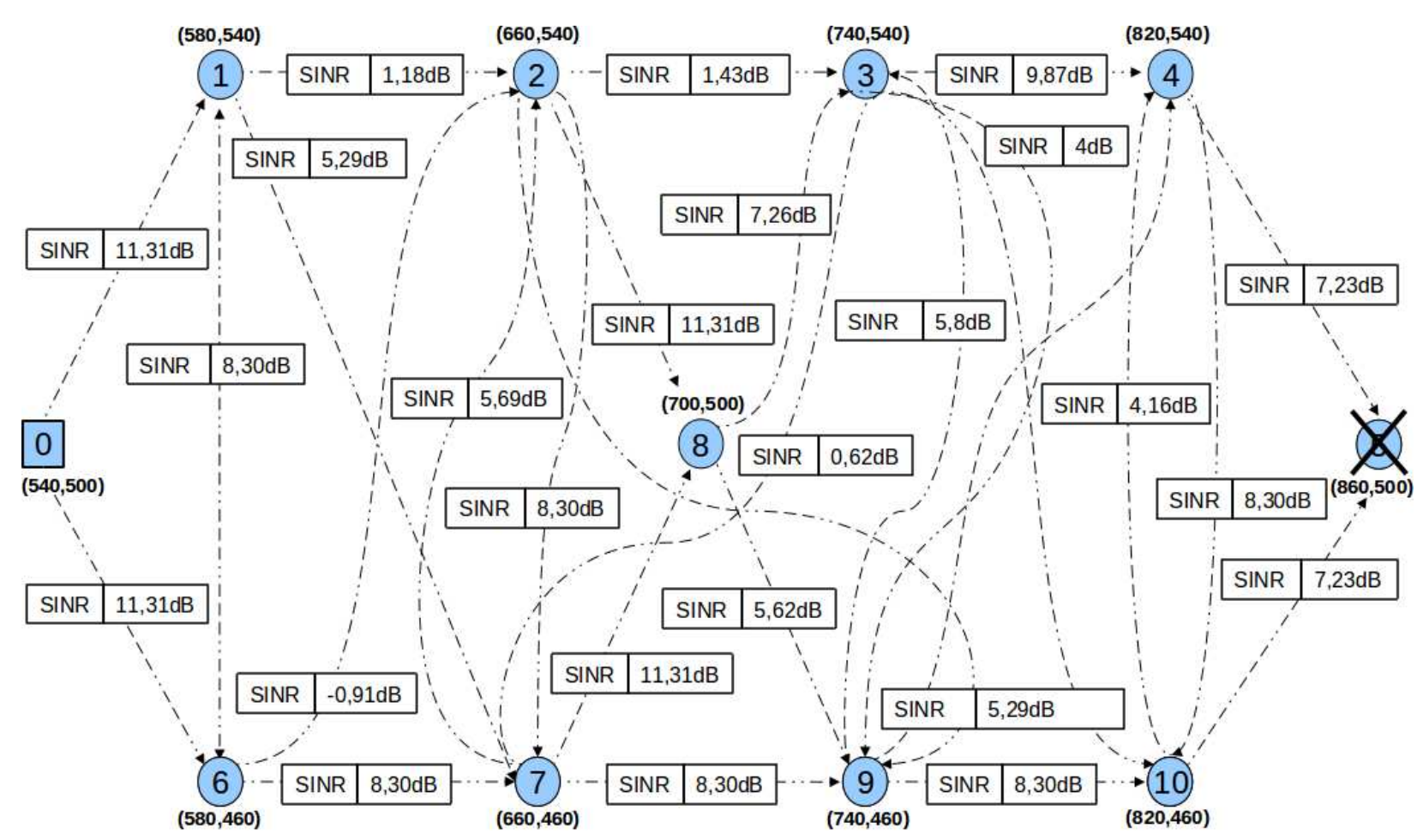

Figura 18: Cenário de simulação composto por 11 nós sem fio.

Fonte: Autoria própria

Logo após esse período inicial caracterizado como o período de convergência do protocolo, o nó de origem começa a transmitir pacotes de dados na direção do nó 5 (destino), até atingir um limite de tempo de simulação de 35 segundos.

As transmissões foram realizadas considerando uma sistema formado por uma única antena transmissora e receptora (SISO), ou seja, sem o auxílio de técnicas MIMO. Como foi citado an- 
teriormente a simulação considerou um modelo de canal Rayleigh, para o qual foram realizados diversos sorteios de canal. Amostrando uma dessas realizações, foi possível analisar a escolha das rotas e taxas de transmissão respectivas, de acordo com o valor de SINR calculado para o enlace sem fio. Para fins de comparação, também capturou-se os resultados utilizando o protocolo OLSR descrito pela RFC3626, ou seja, cuja a rota é definida pelo menor número de saltos.

A Figura a seguir apresenta as rotas escolhidas em ambos os casos:

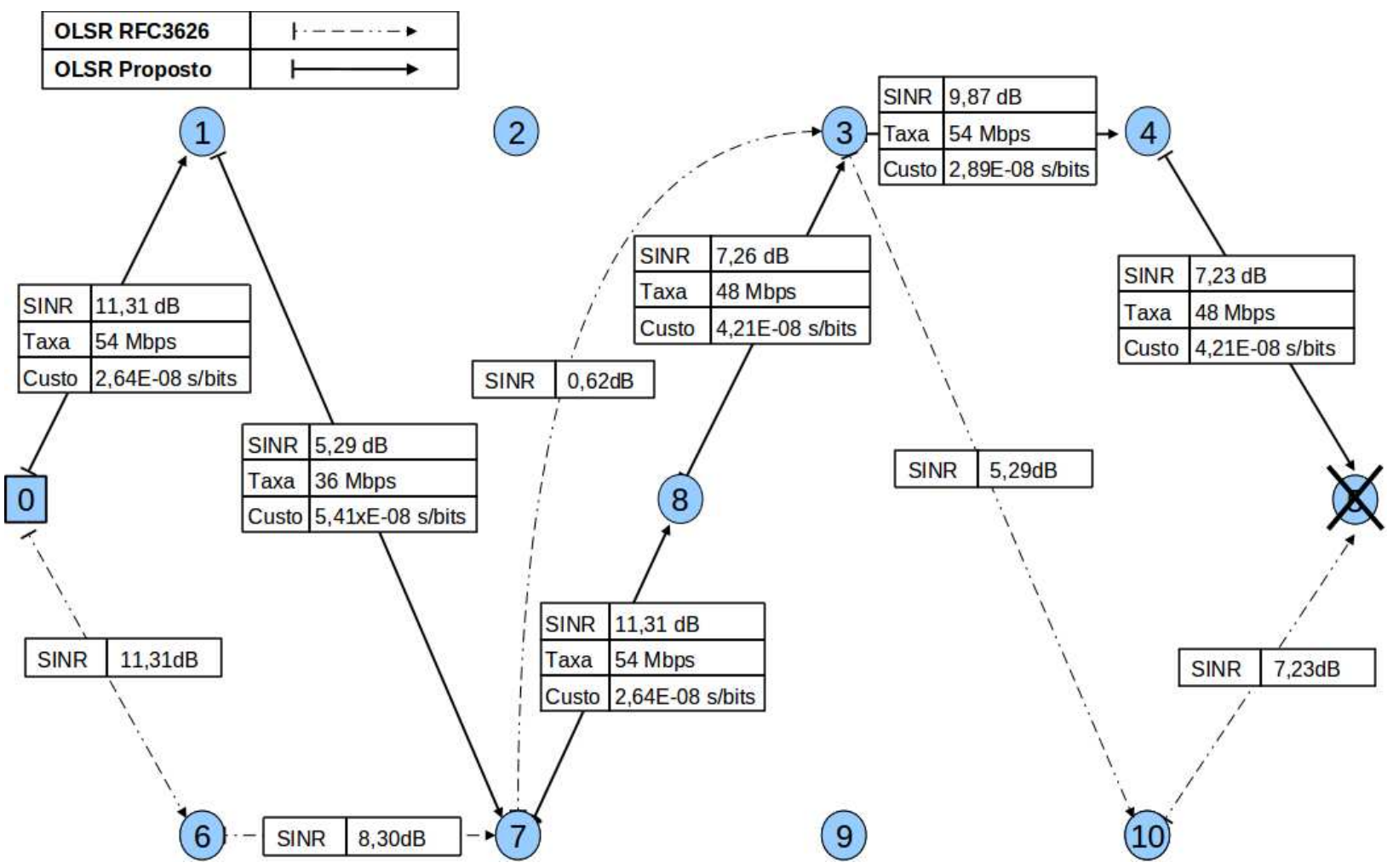

Figura 19: Rotas escolhidas em cenário composto por 11 nós sem fio.

Fonte: Autoria própria

Na Figura 19 a linha pontilhada representa a rota selecionada utilizando o OLSR descrito pela RFC3626. Já a linha contínua representa a rota selecionada utilizando o OLSR proposto. Enquanto o OLSR-RFC3626 busca o menor caminho possível para o destino (independente do estado dos enlaces), o OLSR proposto tenta selecionar os caminhos com melhores condições de canal, de maneira que a vazão fim-a-fim seja a maior possível. Portanto, como pode ser observado na Figura 19, o OLSR definido pela RFC3626 escolheu um caminho com 5 saltos para o destino, enquanto que o OLSR proposto fez o mesmo em 6 saltos. A Tabela 3 apresenta os resultados obtidos.

Como pode ser observado na Tabela 3, utilizando o protocolo OLSR proposto atingiuse um valor de vazão média igual a 1632,19 kbps. Entretanto, utilizando o protocolo OLSR como descrito pela RFC3626, obteve-se uma vazão média de 1186,22 kbps. Ou seja, o modelo 
Tabela 3: RFC3626 vs. OLSR Proposto - Conjunto de medidas realizadas durante a simulação.

\begin{tabular}{ccc}
\hline Medidas & OLSR - RFC3626 & OLSR - Proposto \\
\hline \hline Vazão Média[kbps] & 1186,22 & 1632,19 \\
Atraso Médio[ms] & 480,19 & 220,60 \\
Jitter Médio[ms] & 6,27 & 2,92 \\
Pacotes enviados & 7325 & 7325 \\
Pacotes recebidos & 2172 & 2873 \\
Pacotes perdidos & 5153 & 4452 \\
Pacotes de controle & 298 & 301 \\
Número de saltos & 5 & 6 \\
\hline
\end{tabular}

Fonte: Autoria própria

proposto possibilitou atingir um valor de vazão média aproximadamente $50 \%$ superior, quando comparado com o OLSR descrito pela RFC3626. Ao analisar os demais itens dessa tabela, verificou-se que o uso do OLSR modificado proporcionou uma queda significativa no valor do atraso médio fim-a-fim - de 480,19 ms para 220,60 ms. E esta queda foi ainda mais acentuada em termos do jitter médio - variando de $6,27 \mathrm{~ms}$ à 2,82 ms.

Outro detalhe importante a ser observado na Tabela 3, é o número de pacotes perdidos. Utilizando o OLSR descrito pela RFC3626, 5153 pacotes foram perdidos, enquanto que o OLSR proposto reduziu esse número de perdas para 4452 pacotes. Já o número de pacotes de controle do protocolo trocados entre os nós, sofreu somente um leve aumento - de 298 para 301 pacotes com o OLSR proposto.

Apesar do OLSR proposto exigir um número de saltos superior para atingir o destino, este apresentou melhor desempenho em termos de vazão, atraso, jitter e número de pacotes perdidos. A redução dos valores de atraso e jitter médios, pode ser muito útil no desempenho de aplicativos sensíveis a essas variáveis (tais como aplicativos de voz e vídeo). Já a redução do número de pacotes perdidos proporcionada pelo uso do OLSR proposto, garante por sua vez uma rede mais estável e confiável. Portanto, a capacidade de selecionar rotas cujo os enlaces apresentem melhores valores de SINR, somado com a escolha adaptativa do modo de transmissão, permitem que o modelo proposto garanta melhores resultados quando comparado com o OLSR descrito pela RFC3626. Por final, vale a pena enfatizar que o modelo proposto não causou impacto significativo no número de pacotes de controle trocados entre os elementos da rede.

Buscando visualizar de forma mais clara o ganho proporcionado pelo uso da métrica proposta, considerou-se dois esquemas MIMO: o V-BLAST 2x2 e o Beamforming (BF) 2x2. Mantendo a mesma topologia e a configuração de tráfego utilizada na simulação anterior, realizou-se 
um conjunto de medidas utilizando o OLSR proposto e o OLSR descrito pela RFC3626. A Tabela 4 resume os resultados obtidos.

Tabela 4: RFC3626 vs. OLSR Proposto - Conjunto de medidas realizadas durante a simulação, considerando dois esquemas MIMO distintos.

\begin{tabular}{ccccc}
\hline Medidas & RFC3626/V-BLAST 2x2 & RFC3626/BF. 2x2 & OLSR Prop./V-BLAST 2x2 & OLSR Prop./BF. 2x2 \\
\hline \hline Rota escolhida & $0-1-7-3-10-5$ & $0-1-7-3-10-5$ & $0-1-2-3-9-10-5$ & $0-1-2-3-4-5$ \\
Vazão Média[kbps] & 4000 & 3010,77 & 4000 & 3994,69 \\
Atraso Médio[ms] & 326.762 & 149,369 & 121.356 & 3,766 \\
Jitter Médio[ms] & 3.4283 & 1,6951 & 1.8950 & 0,6534 \\
Pacotes enviados & 7325 & 7325 & 7325 & 7325 \\
Pacotes recebidos & 3660 & 5512 & 4806 & 7314 \\
Pacotes perdidos & 3665 & 1813 & 2519 & 11 \\
Pacotes de controle & 290 & 291 & 290 & 280 \\
Número de saltos & 5 & 5 & 6 & 5 \\
\hline
\end{tabular}

Fonte: Autoria própria

Como pode ser observado na Tabela 4, utilizando o OLSR descrito pela RFC3626, atingiramse valores de vazão de 4000 kbps e 3010,77 kbps para os esquemas V-BLAST 2x2 e Beamforming $2 \times 2$ respectivamente. No caso do V-BLAST $2 \times 2$ a vazão média ficou limitada à taxa máxima de transmissão estabelecida para o fluxo de dados (configurada em $4000 \mathrm{kbps}$ ), tanto para o OLSR-RFC3626 quanto para o OLSR proposto. Já utilizando o OLSR proposto juntamente com o esquema Beamforming 2x2, obteve-se um valor de vazão média de 3994,69 kbps, tornando evidente o ganho proporcionado pelo uso do OLSR proposto.

Parâmetros como atraso e jitter médios tiveram seus valores mais uma vez reduzidos, variando de $326,762 \mathrm{~ms}$ para $121,356 \mathrm{~ms}$ e de 3,4283 ms à 1,8950 ms respectivamente no esquema V-BLAST 2x2. Enquanto que no caso com Beamforming 2x2, esta redução foi de 149,369 ms para 3,766 ms e em termos de jitter, de 1,6951 ms para 0,6534 ms. Quanto ao número de pacotes perdidos, nota-se uma perceptível redução. No esquema V-BLAST 2x2 a redução foi de 3665 para 2519 pacotes perdidos, enquanto que no esquema Beamforming 2x2, foi de 1813 para somente 11 pacotes perdidos. Já o número de mensagens de controle trocada entre os elementos da rede não sofreu impacto significativo.

Portanto, apesar dos pacotes percorrerem um caminho maior utilizando o esquema VBLAST 2x2/OLSR proposto, a busca pelos enlaces com melhores condições de canal (maior valor de SINR) e seleção adaptativa do modo de transmissão, garantiram um desempenho superior quando comparado com o OLSR descrito pela RFC3626. Esse ganho pode ser observado em termos de atraso, jitter e número de pacotes perdidos. Já no caso do Beamforming 2x2/OLSR proposto o número de saltos permaneceu o mesmo, entretanto, o uso de uma nova rota com melhores condições de canal, permitiram ganhos notáveis em todos os parâmetros apresentados na Tabela 4. Para finalizar, vale ressaltar que a combinação do OLSR proposto com esque- 
mas MIMO, mostrou-se ainda mais vantajosa quando comparada com o uso do OLSR proposto isolado (ou seja, sem o auxílio de esquemas MIMO).

A seguir a seção 4.2 busca apresentar a aplicação do modelo proposto em diferentes cenários. Neste âmbito, explorou-se as vantagens proporcionadas pelos esquemas MIMO, considerando dez topologias cuja a posição dos nós foi escolhida aleatoriamente.

\subsection{CENÁRIO DE SIMULAÇÃO 2}

Procurando demonstrar as principais características de comportamento do modelo proposto, variando as distâncias entre os nós posicionados em um cenário plano, esta seção trás os resultados obtidos considerando dez topologias distintas. Para tal, buscou-se sortear a posição dos nós aleatoriamente, de maneira a formar as dez topologias. E para garantir um cenário mais realista no sorteio das posições, estabeleceu-se uma distância mínima entre os nós, de maneira que nenhum nó sobreponha o outro. A Figura 20 apresenta as dez topologias sorteadas. O nó de formato quadrado representa o nó de origem do tráfego, e o nó em formato de " $X$ " representa o nó de destino.

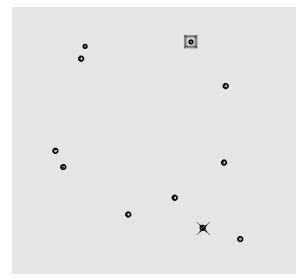

(a) Topologia 1

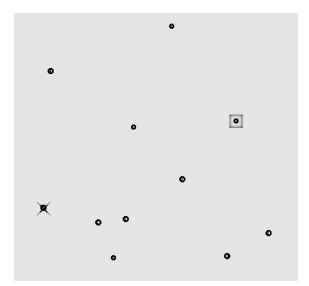

(f) Topologia 6

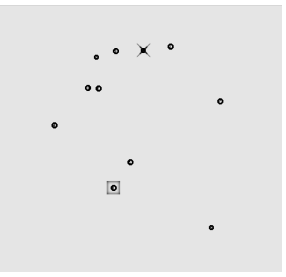

(b) Topologia 2

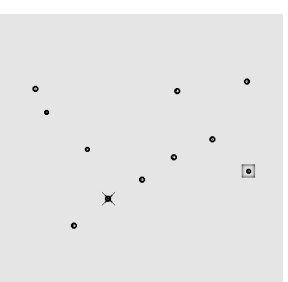

(g) Topologia 7

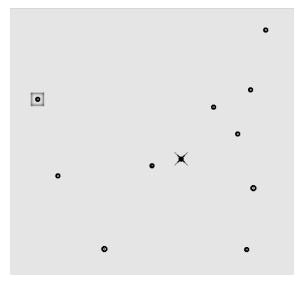

(c) Topologia 3

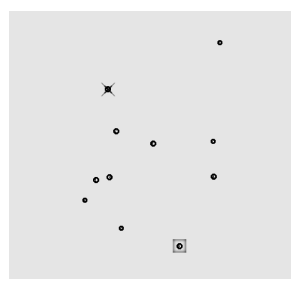

(h) Topologia 8

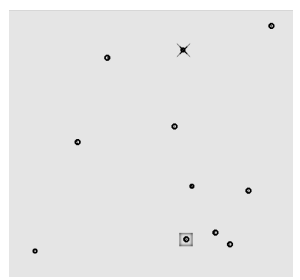

(d) Topologia 4

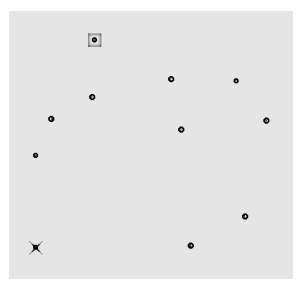

(i) Topologia 9

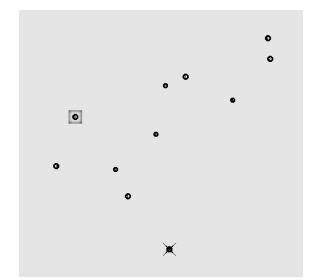

(e) Topologia 5

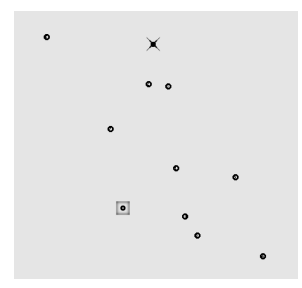

(j) Topologia 10

Figura 20: Conjunto de dez topologias distintas, definidas por sorteio e utilizado nas simulações.

Mais uma vez, buscando facilitar a compreensão e análise dos resultados obtidos, mantevese a configuração do tráfego sugerida na simulação da seção 4.1. Ou seja, considerou-se um único fluxo com taxa de transmissão constante de 4Mbps e tamanho de pacote fixo em 1024 bytes. A potência de transmissão de cada elemento é fixada em 0,0361 Watts. Inicialmente durante um período de 15 segundos, os nós trocam pacotes de HELLO e TC entre si, para que 
todos obtenham conhecimento sobre a condição do enlace e posicionamento dos outros nós da rede.

Cada topologia é composta por 11 nós sem fio, de onde foram capturados valores de vazão, atraso e jitter médios, como também o número de pacotes de controle trocados e pacotes perdidos. Para fins de comparação, a Tabela 5 apresenta os resultados obtidos para cada uma das dez topologias sorteadas, utilizando o protocolo OLSR como descrito pela RFC3626. Tais valores serão utilizados como valores de referência, na tentativa de estabelecer os ganhos proporcionados pelo modelo proposto.

Tabela 5: SISO - Conjunto de medidas realizadas para 10 topologias distintas utilizando o OLSR - RFC3626

\begin{tabular}{c|cccccccccc}
\hline Medidas & Top.1 & Top.2 & Top.3 & Top.4 & Top.5 & Top.6 & Top.7 & Top.8 & Top.9 & Top.10 \\
\hline \hline Vazão Média[kbps] & 2151,81 & 2109,89 & 1849,08 & 2082,09 & 1401,43 & 2046,94 & 2849,36 & 1712,64 & 1862,58 & 2252,3 \\
Atraso Médio[ms] & 276,253 & 213,432 & 294,967 & 317,975 & 187,799 & 293,029 & 161,979 & 287,93 & 352,952 & 257,436 \\
Jitter Médio[ms] & 2,9526 & 2,9995 & 3,0798 & 2,9952 & 2,8220 & 3,1138 & 1,9645 & 3,2092 & 3,5209 & 2,9186 \\
Pcts. enviados & 7325 & 7325 & 7325 & 7325 & 7325 & 7325 & 7325 & 7325 & 7325 & 7325 \\
Pcts. recebidos & 3940 & 3863 & 3385 & 3812 & 2566 & 3748 & 5179 & 3135 & 3410 & 4124 \\
Pcts. perdidos & 3385 & 3462 & 3940 & 3513 & 4759 & 3577 & 2146 & 4190 & 3915 & 3201 \\
Pcts. de controle & 300 & 274 & 291 & 279 & 275 & 251 & 301 & 268 & 297 & 284 \\
\hline
\end{tabular}

Fonte: Autoria própria

O sorteio da posição dos nós no cenário seguiu um padrão determinístico, ou seja, é possível simular novamente as mesmas dez topologias utilizadas para obter os resultados da Tabela 5. Portanto, aplicou-se o modelo proposto nas mesmas dez topologias, de maneira que a Tabela 6 apresenta os resultados obtidos.

Tabela 6: SISO - Conjunto de medidas realizadas para 10 topologias distintas utilizando o OLSR proposto

\begin{tabular}{c|cccccccccc}
\hline Medidas & Top.1 & Top.2 & Top.3 & Top.4 & Top.5 & Top.6 & Top.7 & Top.8 & Top.9 & Top.10 \\
\hline \hline Vazão Média[kbps] & 2415,06 & 2753,01 & 2855,25 & 2536,81 & 2714,38 & 2325,58 & 3200,05 & 2298,3 & 2247,88 & 2940,52 \\
Atraso Médio[ms] & 130,286 & 112,403 & 126,595 & 168,791 & 68,0738 & 125,123 & 53,7866 & 108,101 & 145,627 & 104,264 \\
Jitter Médio[ms] & 2,0659 & 1,8639 & 1,7909 & 2,24995 & 1,7190 & 2,3967 & 1,2909 & 2,1347 & 2,3561 & 1,7225 \\
Pcts. enviados & 7325 & 7325 & 7325 & 7325 & 7325 & 7325 & 7325 & 7325 & 7325 & 7325 \\
Pcts. recebidos & 4422 & 5039 & 5227 & 4645 & 4969 & 4256 & 5859 & 4205 & 4116 & 5384 \\
Pcts. perdidos & 2903 & 2286 & 2098 & 2680 & 2356 & 3069 & 1466 & 3120 & 3209 & 1941 \\
Pcts. de controle & 309 & 275 & 299 & 267 & 278 & 246 & 305 & 262 & 299 & 282 \\
\hline
\end{tabular}

Fonte: Autoria própria

E buscando facilitar a análise e comparação dos resultados, a Figura 21 ilustra somente os valores de vazão média para o OLSR-RFC3626 e o OLSR proposto, para cada uma das dez topologias sorteadas.

Como pode ser observado na Figura 21, utilizando o OLSR proposto todas as dez topologias sorteadas apresentaram valores de vazão média superiores aos obtidos com OLSR-RFC3626. 


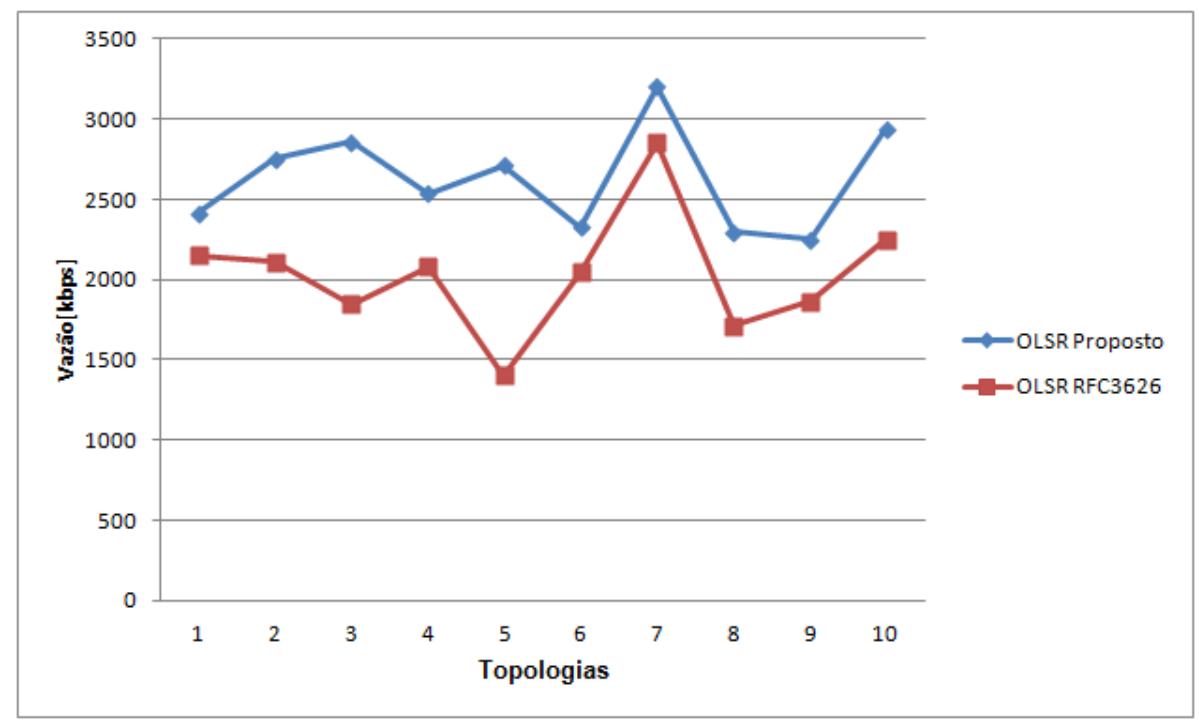

Figura 21: Comparativo dos valores de vazão média obtidos, utilizando o OLSR proposto e o OLSR descrito pela RFC3626.

\section{Fonte: Autoria própria}

Dependendo da disposição dos elementos, esse ganho de vazão variou de $12 \%$ até $93 \%$. Ou seja, a aplicação do modelo proposto é capaz de gerar um ganho significativo de vazão quando comparado com o OLSR-RFC3626. A comparação de outros parâmetros como o atraso, jitter, número de pacotes de controle enviados e pacotes perdidos, pode ser melhor observada na Figura 22.

As Figuras 22(a) e 22(b) apresentam os valores de atraso e jitter para cada uma das topologias. Como pode ser observado, o uso do OLSR proposto gerou uma redução significativa desses valores em todas as topologias apresentadas. Tal característica pode ser muito útil para aplicativos sensíveis a altos valores de atraso e jitter. A queda nos valores do atraso ficaram em torno de 47\% e 66\%, em relação ao obtido com OLSR-RFC3626. Enquanto que os valores de jitter tiveram reduções de $23 \%$ até $41 \%$, dependendo da disposição dos elementos.

Já as Figuras 22(c) e 22(d) ilustram o número de pacotes perdidos e pacotes de controle enviados respectivamente. O número de pacotes perdidos utilizando o OLSR proposto é visivelmente inferior em todas as topologias simuladas, garantindo por sua vez uma rede mais estável e confiável. O redução no número de pacotes perdidos foi de $14 \%$ à $50 \%$ dependendo da topologia. E ao analisar o número de pacotes de controle enviados, nota-se que independentemente do protocolo utilizado (OLSR-RFC3626 ou OLSR proposto), o número de mensagens trocadas basicamente se manteve em todos os cenário simulados. Ou seja, o uso do modelo proposto não causou nenhum impacto significativo, no número de mensagens de controle trocadas entre os elementos da rede. 


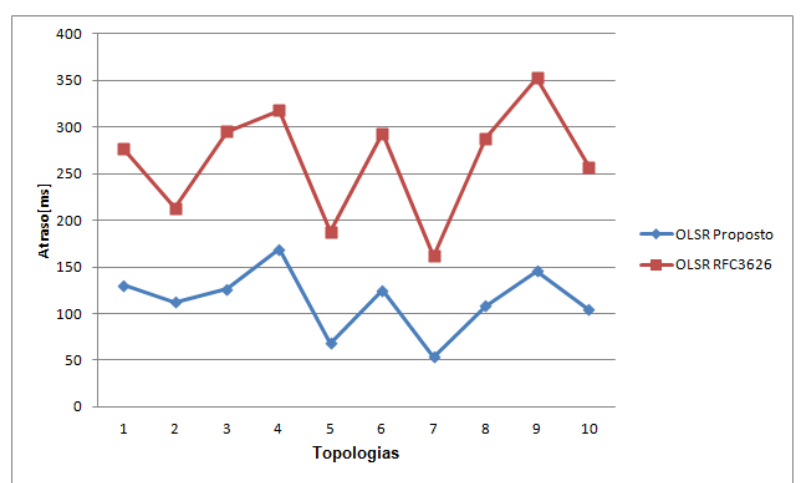

(a) SISO - Atraso

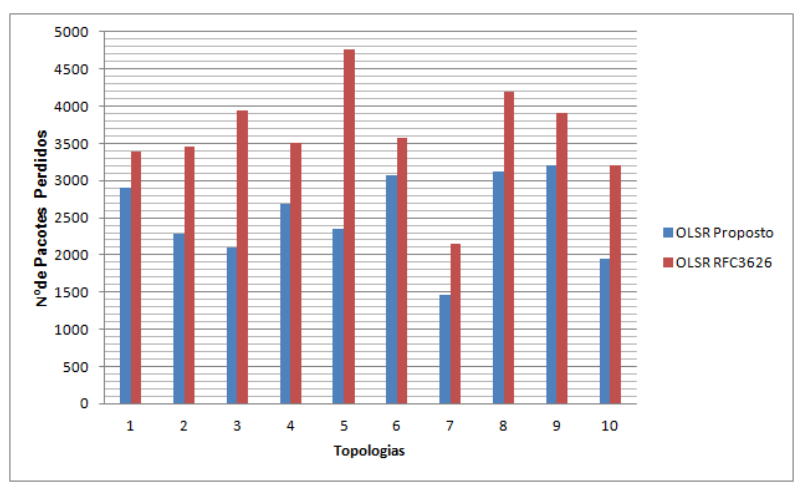

(c) SISO - Número de pacotes perdidos

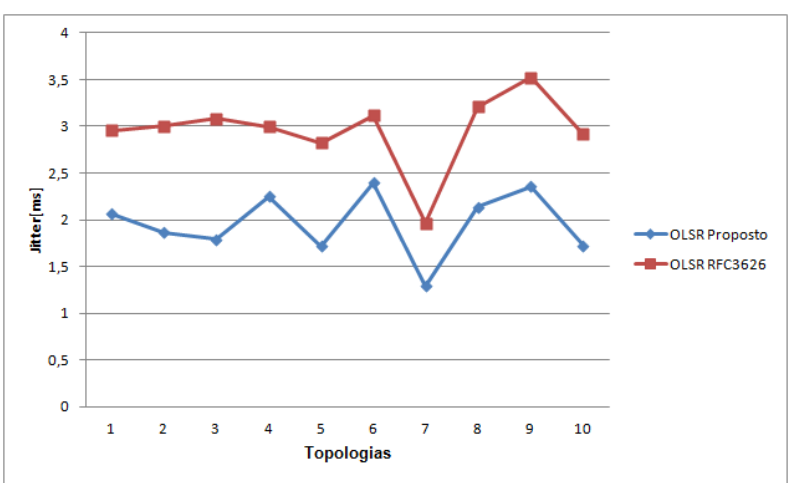

(b) SISO - Jitter

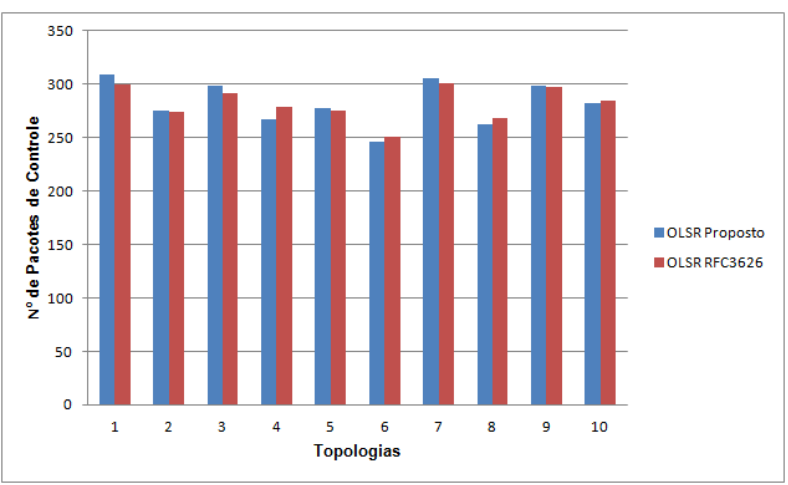

(d) SISO - Número de pacotes de controle

Figura 22: Comparativo dos parâmetros de rede obtidos, utilizando o OLSR proposto e o OLSR descrito pela RFC3626.

Até este ponto no presente trabalho, a maior das parte das simulações realizadas simplesmente comparou os resultados obtidos utilizando o OLSR proposto e o OLSR como descrito pela RFC3626. Para finalizar, decidiu-se combinar o uso do modelo proposto com as vantagens proporcionadas pelos esquemas MIMO. Dentre os esquemas MIMO existentes, escolheu-se utilizar: o Beamforming (BF) 2x2, Alamouti 2x2 e o esquema V-BLAST $2 \times 2$.

Seguindo essa premissa, a Figura 23 apresenta os valores de vazão médios para cada esquema MIMO. Os resultados obtidos sem o auxílio desses esquemas também são apresentados para fins de comparação.

Na Figura 23 as linhas com marcações em formato de quadrado e losango respectivamente, representam a vazão média utilizando o OLSR descrito pela RFC3626 e o OLSR proposto para cada topologia. Já as demais linhas representam os resultados atingidos, utilizando a combinação do OLSR proposto com uma determinado esquema MIMO. Como pode ser observado em todas as topologias, o uso de esquemas MIMO em conjunto com o OLSR proposto, geraram um ganho de vazão ainda superior quando comparado os ganhos proporcionados pelo OLSR proposto isolado (sem o auxílio de esquemas MIMO). Por fim, as técnicas V-BLAST 2x2 e Be- 


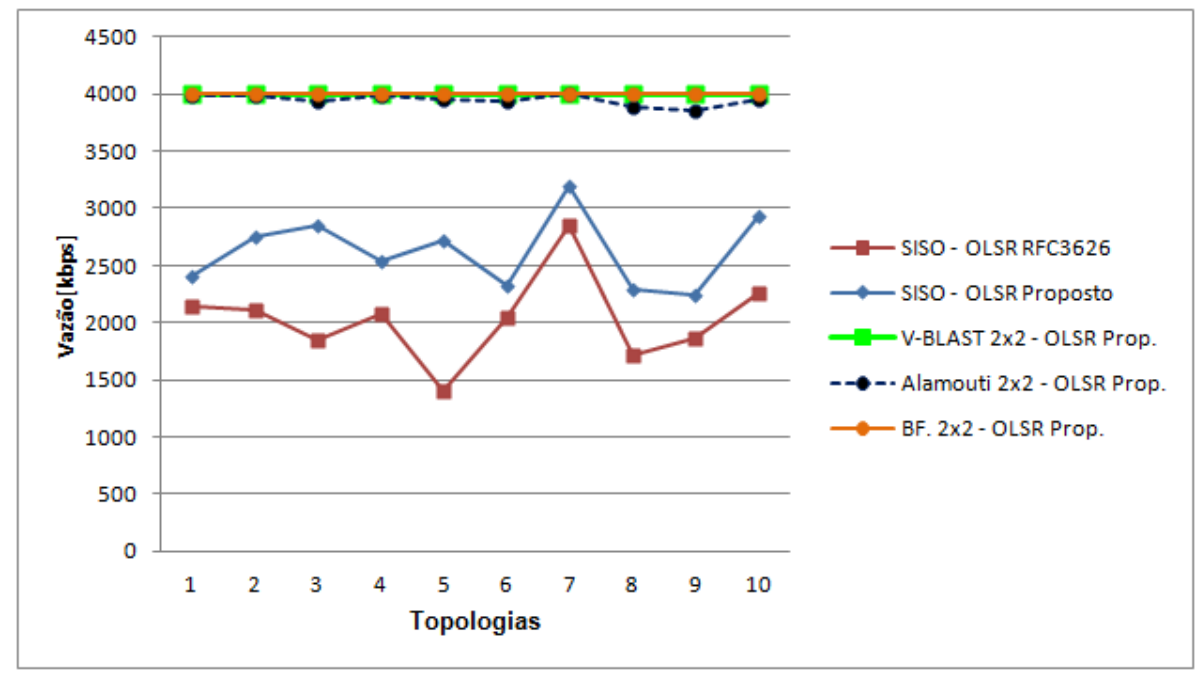

Figura 23: Comparativo dos valores de vazão média obtidos, utilizando combinações do OLSR proposto com esquemas MIMO distintos.

\section{Fonte: Autoria própria}

amforming $2 \times 2$ juntamente com o OLSR proposto, foram as combinações que possibilitaram atingir os valores mais altos em termos de vazão média (se igualando a taxa de transmissão máxima estabelecida para o fluxo de dados - 4Mbps).

Outros parâmetros como o atraso, jitter, número de pacotes perdidos e pacotes de controle, também foram medidos com o intuito de analisar o impacto causado pela combinação desses esquemas nos mesmos. Portanto, a Figura 24 apresenta essas medidas.

As Figuras 24(a) e 24(b) apresentam as medidas de atraso e jitter respectivamente. Ao analisar ambas figuras fica evidente que a combinação dos esquemas MIMO e o OLSR proposto resultaram em valores de atraso e jitter inferiores aos obtidos somente utilizando o OLSR proposto (sem o auxílio de qualquer técnica MIMO). O mesmo pode ser observado em termos de pacotes perdidos, conforme ilustra a 24(c). O número de pacotes perdidos também foi reduzido de forma significativa. No entanto, o número de mensagens de controle trocadas entre os elementos da rede mais uma vez se manteve, como ilustra a Figura 24(d).

A combinação da técnica Beamforming 2x2 juntamente com o OLSR proposto, apresentou os menores valores em termos de atraso, jitter e número de pacotes perdidos. Portanto, levando em consideração o desempenho da rede, esta seria a melhor combinação a ser utilizada em redes que além de exigirem baixos valores de atraso e jitter, também necessitem de maior estabilidade. Entretanto, vale a pena enfatizar que o uso da técnica Alamouti $2 \times 2$ também possibilitou atingir resultados próximos. Dada a maior simplicidade da técnica de Alamouti em relação ao Beamforming (que requer o conhecimento do canal no transmissor), podemos afirmar 


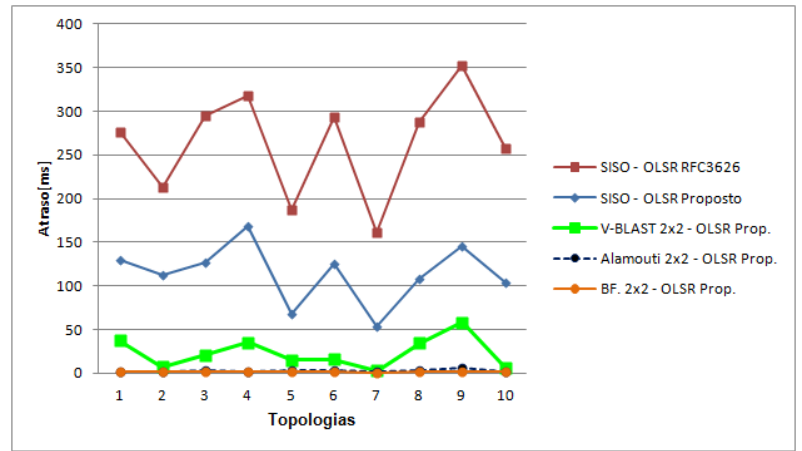

(a) Atraso

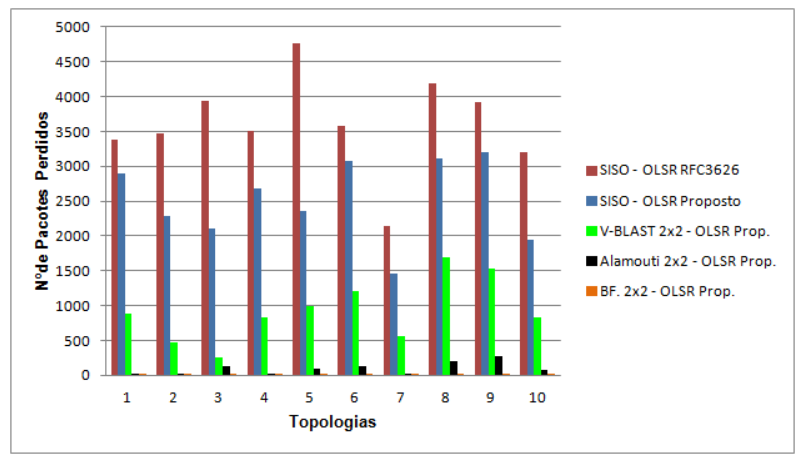

(c) Número de pacotes perdidos

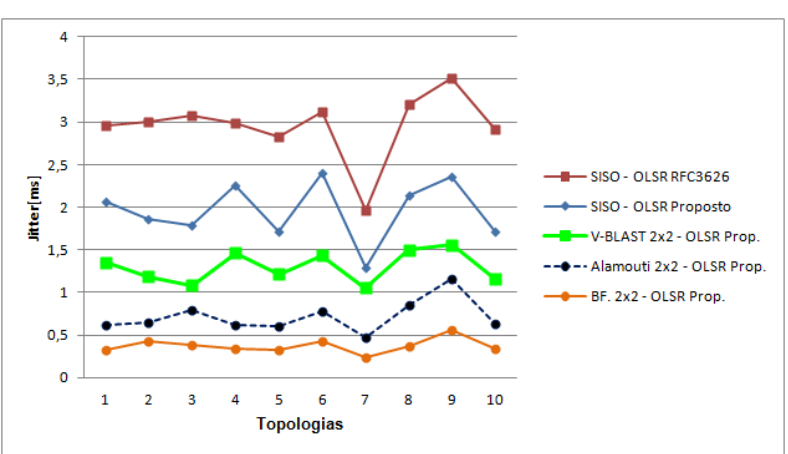

(b) Jitter

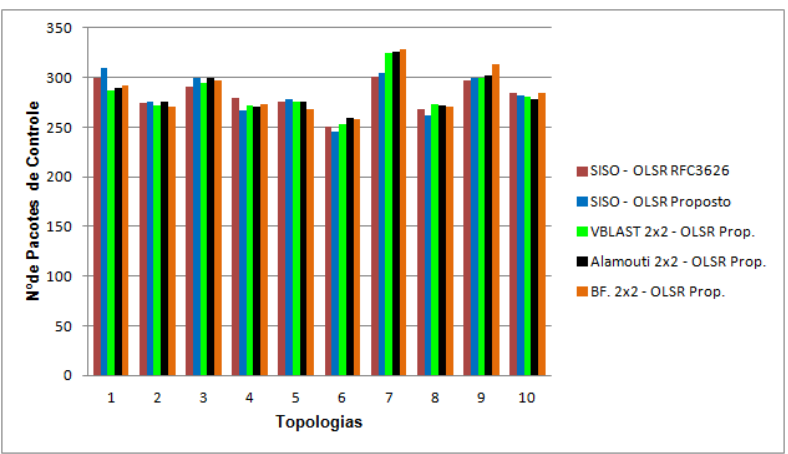

(d) Número de pacotes de controle

Figura 24: Comparativo dos diversos parâmetros de rede obtidos, utilizando combinações do OLSR proposto com esquemas MIMO distintos.

que ela seria uma boa opção na prática para ser usada em conjunto com o OLSR proposto. 


\section{CONSIDERAÇÕES FINAIS}

Este trabalho investigou o uso de uma proposta de roteamento adaptativa em redes sem fio múltiplos saltos, utilizando uma versão modificada do protocolo OLSR. De acordo com a condição do canal, o nó determina a taxa de transmissão e consequente modulação, que irá proporcionar a maior vazão possível no enlace. Essa informação é repassada para a camada de rede, que por sua vez com auxílio da versão modificada do protocolo de roteamento, seleciona a melhor rota (maior vazão) no percurso fim-a-fim. Através de simulações computacionais, os resultados foram obtidos e comparados com a versão do protocolo OLSR descrita pela RFC3626.

Nas simulações realizadas na subseção 4.1, ficou claro o ganho proporcionado pelo uso do modelo proposto. A vazão média calculada apresentou um ganho de aproximadamente 50\% quando comparada com o OLSR-RFC3626. A diminuição tanto do atraso quanto do jitter, proporcionadas pelo esquema proposto, podem ser muito interessantes para aplicações sensíveis a esses tipos de variáveis. Já a redução observada no número pacotes perdidos, garante uma importante melhora em características essenciais, tais como a confiabilidade e estabilidade da rede. Por final, a combinação do uso de esquemas MIMO com o modelo proposto, demonstrou ser ainda mais eficiente e portanto, melhorando ainda mais os resultados obtidos.

Na subseção 4.2 dez topologias foram sorteadas, buscando garantir que o comportamento observado na subseção 4.1, pudesse ser replicado considerando diferentes distribuições entre os elementos da rede. Seguindo com essa premissa, os resultados demonstram que o uso do esquema proposto é vantajoso tanto em termos de vazão, como atraso, jitter e número de pacotes perdidos. A combinação do uso de esquemas MIMO com o modelo proposto, demonstrou ser ainda mais eficiente. Por fim, a combinação dos esquemas MIMO: V-BLAST 2x2 e Beamforming $2 \times 2$ juntamente com o OLSR proposto, foram as combinações que apresentaram os melhores resultados em termos de vazão. Já considerando os demais parâmetros analisados, o uso do esquema Beamforming $2 \times 2$ em conjunto com o modelo proposto foi a combinação que proporcionou os melhores resultados em termos de atraso, jitter e número de pacotes perdidos. Entretanto, apesar do esquema Alamouti $2 \times 2$ apresentar desempenho ligeiramente inferior ao do Beamforming $2 \times 2$, ele tem como vantagem o fato de não requerer o conhecimento do canal 
no transmissor (GOLDSMITH, 2005) e portanto ser mais simples. Tal característica permite que ele torne um opção interessante do ponto de vista prático, para ser aplicado em sistema de comunicação sem fio.

A fim de dar continuidade a este trabalho, sugere-se realizar as mesmas medidas aqui apresentadas, porém verificando o impacto causado ao realizar várias transmissões simultâneas. Outro cenário que vale a pena ser investigado, é o comportamento e influência do protocolo de roteamento frente a mobilidade dos nós da rede. 


\section{REFERÊNCIAS}

AKYILDIZ, I. F.; WANG, X. Cross-layer design in wireless mesh networks. IEEE Transactions on Vehicular Technology, v. 57, n. 9, p. 1061-1076, mar. 2008.

ALAMOUTI, S. A simple transmit diversity technique for wireless communications. Selected Areas in Communications, IEEE Journal on, IEEE, v. 16, n. 8, p. 1451-1458, 1998.

BANSAL, L. K.; TRIVEDI, A. Comparative Study of Space-Time Trellis Code Concatenated With Space-Time Block Code MC-CDMA System. 2009 IEEE International Advance Computing Conference, IEEE, v. 099, n. March, p. 1099-1102, mar. 2009. Disponível em: $<$ http://ieeexplore.ieee.org/lpdocs/epic03/wrapper.htm?arnumber=4809167 $>$.

BELDING-ROYER, E. Routing approaches in mobile ad hoc networks. In: S. Basagni, M. Conti, S. G.; STOJMENOVIC, I. (Ed.). Ad Hoc Networking. New York, NY: IEEE Press Wiley, 2003. cap. 10.

CARDOSO, K. V.; REZENDE, J. F. de. Adaptação automática de taxa em redes 802.11 densas. XVI Simpósio Brasileiro de Redes de Computadores - SBRC2008, p. 467-480, maio 2008.

CHIANG, C. C. et al. Routing in clustered multihop, mobile wireless networks with fading channel. In: Wireless Networks. [S.1.]: Citeseer, 1997. p. 197-211.

CHLAMTAC, I. Mobile ad hoc networking: imperatives and challenges. Ad Hoc Networks, v. 1, n. 1, p. 13-64, jul. 2003. ISSN 15708705. Disponível em: $<$ http://linkinghub.elsevier.com/retrieve/pii/S1570870503000131>.

CLAUSEN, T.; JACQUET, P. Optimized link state routing protocol (OLSR). [S.1.], out. 2003. 75 p. Disponível em: < http://portal.acm.org/citation.cfm?id=RFC3626>.

FOSCHINI, G. J. et al. Analysis and performance of some basic space-time architectures. IEEE Journal on Selected Areas in Communications, v. 21, n. 3, p. 303-320, 2003.

GARCIA-LUNA-ACEVES, J. J.; SPOHN, M. Source-Tree Routing in Wireless Networks Â£. Proceedings Seventh International Conference on Network Protocols, i, p. 273-282, 1999.

GOLDSMITH, A. Wireless Communications. New York, NY, USA: Cambridge University Press, 2005. ISBN 0521837162.

HAYKIN, S.; MOHER, M. Sistemas Modernos de Comunicações Wireless. Porto Alegre: Bookman, 2008. 580 p.

HOLLAND, G.; VAIDYA, N.; BAHL, P. A rate-adaptive MAC protocol for multi-hop wireless networks. In: Proceedings of the 7th Annual International Conference on Mobile Computing and Networking. New York, NY, USA: ACM, 2001. p. 236-251.

HUITEMA, C. Routing in the Internet. 2. ed. [S.1.]: Prentice Hall, 2000. xiii + 384 p. 
IEEE 802.11g. Amendment 4 to Part 11: Wireless LAN Medium Access Control (MAC) and Physical Layer (PHY) Specifications: Further Higher Data Rate Extension in the $2.4 \mathrm{GHz}$ Band. IEEE Standards, 2003.

ISSARIYAKUL, T.; HOSSAIN, E. Introduction to Network Simulator NS2. New York, NY: Springer Science+Business media LLC, 2008.

JACQUET, P.; MUHLETHALER, P.; CLAUSEN, T. Optimized link state routing protocol for ad hoc networks. 2001 IEEE INMIC, p. 62-68, 2001.

JOHNSON, D.; AICHELE, C.; NTLATLAPA, N. A simple pragmatic approach to mesh routing using BATMAN. In: 2nd IFIP International Symposium on Wireless Communications and Information Technology in Developing Countries. [S.1.: s.n.], 2008. p. 10.

JOHNSON, D. B.; MALTZ, D. A. Dynamic source routing in ad hoc wireless networks. Forbes, v. 353, p. 153-181, 1996.

KAKITANI, M. T. Uma proposta inter-camadas em redes sem fio múltiplos saltos para otimização e estabilidade de rotas. Tese (Dissertação de Mestrado) — Universidade Tecnológica Federal do Paraná, 2010.

KAMERMAN, A.; MONTEBAN, L. WaveLAN-II: a high-performance wireless LAN for the unlicensed band. Bell Labs Technical Journal, v. 2, n. 3, p. 118-133, jul. 1997.

KIM, J.; KIM, S.; CHOI, S. CARA: Collision-Aware Rate Adaptation for IEEE 802.11 WLANs. Proceedings IEEE INFOCOM 2006 25TH IEEE International Conference on Computer Communications, p. 1-11, 2006.

KIM, S.; LEE, S.; CHOI, S. The impact of IEEE 802.11 MAC strategies on multi-hop wireless mesh networks. IEEE Workshop on Wireless Mesh Networks (WiMesh), p. 38-47, 2006.

KNOPP, R.; HUMBLET, P. A. On coding for block fading channels. IEEE Transactions on Information Theory, IEEE, v. 46, n. 1, p. 189-205, jan. 2000 . ISSN 00189448.

KO, Y.-b.; VAIDYA, N. H. Location-Aided Routing (LAR) in mobile ad hoc networks. Proceedings of the 4th annual ACMIEEE international conference on Mobile computing and networking MobiCom 98, v. 6, p. 307-321, 1998.

LACAGE, M. et al. IEEE 802.11 rate adaptation: a practical approach. In: Proceedings of the 7th ACM International Symposium on Modeling, Analysis and Simulation of Wireless and Mobile Systems. New York, NY, USA: ACM, 2004. p. 126-134. ISBN 1581139535.

LATIFF, L.; FISAL, N. Routing protocols in wireless mobile ad hoc network - a review. 9th Asia-Pacific Conference on Communications, Ieee, v. 2, p. 600-604, 2003. Disponível em: $<$ http://ieeexplore.ieee.org/lpdocs/epic03/wrapper.htm?arnumber=1274428 $>$.

LOYKA, S.; GAGNON, F.; MEMBER, S. Performance analysis of the V-BLAST algorithm: an analytical approach. IEEE Transactions on Wireless Communications, v. 3, n. 4, p. 1326 1337, jul. 2004.

MALKAMAKI, E.; LEIB, H. Coded diversity on block-fading channels. IEEE Transactions on Information Theory, IEEE, v. 45, n. 2, p. 771-781, mar. 1999. 
MATHWORKS, T. MatLab 7 - Getting Started guide. 2007. Disponível em: $<$ http://www.mathworks.com $>$.

PARK, V. D.; CORSON, M. S. A Highly Adaptive Distributed Routing Algorithm f or Mobile Wireless Networks. In: Proceedings of INFOCOM 97. [S.1.]: IEEE Comput. Soc. Press, 1997. p. 1405-1413. ISBN 0818677805.

PERKINS, C. E.; BHAGWAT, P. Highly Dynamic ( DSDV ) for Mobile Computers Routing. SIGCOMM Comput Commun Rev, v. 24, p. 234-244, 1994.

PERKINS, C. E.; ROYER, E. M. Ad-hoc On-Demand Distance Vector Routing. ACM SIGMOBILE Mobile Computing and Communications Review, v. 6, p. 90-100, 1999.

RAPPAPORT, T. S. Wireless Communications: Principles and Practice. 2. ed. Upper Saddle River, NJ: Prentice Hall, 2002.

ROS, F. J. UM-OLSR. 2009. Disponível em: <http://masimum.dif.um.es/?Software:UMOLSR $>$.

ROSIERS, A. des; SIEGEL, P. On performance bounds for space-time codes on fading channels. IEEE Transactions on Communications, IEEE, v. 52, n. 10, p. 1688-1697, out. 2004. ISSN 0090-6778.

ROYER, E.; TOH, C. A review of current routing protocols for ad hoc mobile wireless networks. Personal Communications, IEEE, IEEE, v. 6, n. 2, p. 46-55, 1999.

RUBINSTEIN, M. et al. A Survey on Wireless Ad Hoc Networks. In: PUJOLLE, G. (Ed.). Mobile and Wireless Communication Networks. Springer Boston, 2006. v. 211, p. 1-33. Disponível em: < http://www.springerlink.com/index/HMJ41211N0352282.pdf >.

SADEGHI, B. et al. OAR: an opportunistic auto-rate media access protocol for ad hoc networks. Wireless Networks, Kluwer Academic Publishers, v. 11, n. 1, p. 39-53, jan. 2005.

SHAH, S. et al. Performance Evaluation of Ad Hoc Routing Protocols Using NS2 Simulation. Performance Evaluation, 2008.

TANENBAUM, A. S. Redes de computadores. trad. 4 ed. [S.1.]: CAMPUS, 2003.

TAROKH, V.; SESHADRI, N.; CALDERBANK, A. Space-time codes for high data rate wireless communication: performance criterion and code construction. IEEE Transactions on Information Theory, v. 44, n. 2, p. 744-765, mar. 1998. ISSN 00189448.

THE Network Simulator - ns-2. 2010. Disponível em: $<$ http://www.isi.edu/nsnam/ns $>$.

TSE, D.; VISWANATH, P. Fundamentals of wireless communication. [S.1.]: Cambridge University Press, 2005. 586 p. ISBN 9780521845274.

VARAIYA, W. R.; P.P. Capacity of classes of Gaussian channels. SIAM Journal on Applied Mathematics, v. 16, n. 6, p. 1350-1393, 1968.

WANG, Z.; CROWCROFT, J. Quality-of-service routing for supporting multimedia applications. IEEE Journal of Selected Areas in Communications, v. 14, n. 7, p. 1228-1234, set. 1996. 
XU, K.; GERLA, M.; BAE, S. Effectiveness of RTS / CTS handshake in IEEE 802.11 based ad hoc networks. Ad Hoc Networks, v. 1, n. 1, p. 107-123, jul. 2003. ISSN 15708705.

ZHANG, Q.; ZHANG, Y.-q. Cross-Layer design for QoS support in multihop wireless networks. In: Proceedings of the IEEE. [S.1.: s.n.], 2008. v. 96, no. 1, p. 64-76. 


\section{APÊNDICE A - TABELAS: TAXA DE TRANSMISSÃO X SINR - MIMO}

Tabela A-1: Alamouti 2x2 - Faixas de SINR vs. Taxa de Transmissão escolhida

\begin{tabular}{cc}
\hline Faixas de SINR & Taxa de Transmissão \\
\hline \hline$-10 \mathrm{~dB} \rightarrow-7.22 \mathrm{~dB}$ & $6 \mathrm{Mbps}$ \\
$-7.22 \mathrm{~dB} \rightarrow-5.42 \mathrm{~dB}$ & $9 \mathrm{Mbps}$ \\
$-5.42 \mathrm{~dB} \rightarrow-3.41 \mathrm{~dB}$ & $12 \mathrm{Mbps}$ \\
$-3.41 \mathrm{~dB} \rightarrow-1.31 \mathrm{~dB}$ & $18 \mathrm{Mbps}$ \\
$-1.31 \mathrm{~dB} \rightarrow 1.21 \mathrm{~dB}$ & $24 \mathrm{Mbps}$ \\
$1.21 \mathrm{~dB} \rightarrow 3.94 \mathrm{~dB}$ & $36 \mathrm{Mbps}$ \\
$3.94 \mathrm{~dB} \rightarrow 5.73 \mathrm{~dB}$ & $48 \mathrm{Mbps}$ \\
$5.73 \mathrm{~dB} \rightarrow \infty$ & $54 \mathrm{Mbps}$ \\
\hline
\end{tabular}

Fonte: Autoria própria

Tabela A-2: V-BLAST - Faixas de SINR vs. Taxa de Transmissão escolhida

\begin{tabular}{cc}
\hline Faixas de SINR & Taxa de Transmissão \\
\hline \hline$-10 \mathrm{~dB} \rightarrow-5.46 \mathrm{~dB}$ & $6 \mathrm{Mbps}$ \\
$-5.46 \mathrm{~dB} \rightarrow-3.63 \mathrm{~dB}$ & $9 \mathrm{Mbps}$ \\
$-3.63 \mathrm{~dB} \rightarrow-1.57 \mathrm{~dB}$ & $12 \mathrm{Mbps}$ \\
$-1.57 \mathrm{~dB} \rightarrow 0.59 \mathrm{~dB}$ & $18 \mathrm{Mbps}$ \\
$0.59 \mathrm{~dB} \rightarrow 3.20 \mathrm{~dB}$ & $24 \mathrm{Mbps}$ \\
$3.20 \mathrm{~dB} \rightarrow 6.08 \mathrm{~dB}$ & $36 \mathrm{Mbps}$ \\
$6.08 \mathrm{~dB} \rightarrow 7.96 \mathrm{~dB}$ & $48 \mathrm{Mbps}$ \\
$7.96 \mathrm{~dB} \rightarrow \infty$ & $54 \mathrm{Mbps}$ \\
\hline
\end{tabular}

Fonte: Autoria própria 
Tabela A-3: Beamforming 2x2 - Faixas de SINR vs. Taxa de Transmissão escolhida

\begin{tabular}{cc}
\hline Faixas de SINR & Taxa de Transmissão \\
\hline \hline$-10 \mathrm{~dB} \rightarrow-8.43 \mathrm{~dB}$ & $9 \mathrm{Mbps}$ \\
$-8.43 \mathrm{~dB} \rightarrow-6.42 \mathrm{~dB}$ & $12 \mathrm{Mbps}$ \\
$-6.42 \mathrm{~dB} \rightarrow-4.32 \mathrm{~dB}$ & $18 \mathrm{Mbps}$ \\
$-4.32 \mathrm{~dB} \rightarrow-1.79 \mathrm{~dB}$ & $24 \mathrm{Mbps}$ \\
$-1.79 \mathrm{~dB} \rightarrow 0.93 \mathrm{~dB}$ & $36 \mathrm{Mbps}$ \\
$0.93 \mathrm{~dB} \rightarrow 2.72 \mathrm{~dB}$ & $48 \mathrm{Mbps}$ \\
$2.72 \mathrm{~dB} \rightarrow \infty$ & $54 \mathrm{Mbps}$ \\
\hline
\end{tabular}

Fonte: Autoria própria 